\title{
Zwischen Diplomatie und malerischem Furor. Rubens und Europa
}

Von

\section{Markus A. Castor}

Mit dem Madrider Raub der Europa resümierte Peter Paul Rubens 1629 auf sensibelstem malerischem Niveau und auf der Höhe seines Ruhms eine Erfolgsrezeptur. Die ebenso befreiende wie freie Kopie nach Tizians um 1560 geschaffenem Gemälde (Abb. 1) zeigt das Vermögen des Malers, mit seinen Bildern die herausragenden Leistungen abendländischer Malerei einzuholen und sie in der Anverwandlung als ureigene Schöpfung wieder ,auszugeben"1. Die Methode des selbstnobilitierenden „Kunstraubs“, der sich nicht mit graphischer Vervielfältigung oder bloßer Kopie zufrieden geben konnte, setzte die konzentrierte Arbeit vor Ort sowie die Zugänglichkeit der Meisterwerke voraus. Besonders am spanischen Hof mit seinem burgundischen Zeremoniell und der Unzugänglichkeit der königlichen Appartements war dies keine Selbstverständlichkeit für einen Maler des 17. Jahrhunderts. Und so erzählt das Gemälde bereits von sich aus von der Sonderstellung Rubens'. Sie zeichnet sich durch die Verbindung von Künstlerreise, diplomatischem Auftrag und der Selbstkonstruktion des Malers aus, ein Künstlerselbstbild, das nachdrücklich auf den mit dem Reisen verbundenen Status baut. Für diesen konkreten Fall kopierender Aneignung wird man unterstellen müssen, daß sich Rubens mit dem nachschaffenden Künstlervergleich in die seit der Antike

\footnotetext{
${ }^{1}$ Für essentielle Hinweise und den Austausch zur Frage der Künstlerreise im 17. Jahrhundert sei an dieser Stelle Anja Castor, Friedrich Polleroß und Godehard Janzing gedankt. Für Grundlegendes zum Verständnis der Bildsprache, insbesondere des Peter Paul Rubens, danke ich Wilhelm Schlink.

Die Bilder mit den Götterliebschaften, die Tizian zwischen 1553 und 1562 für Philipp II. von Spanien malte, sind als malerische Interpretationen der Ovidschen Metamorphosen zu lesen, mit denen Tizian, die Malereien als Poesie titulierend, die Leistungsfähigkeit der Malerei im Kontext des Paragone demonstriert. Während Rubens' Aufenthalt war das Bild als Pendant zu Tizians Danaë im Privatappartement des Alcázar zu sehen. Rubens' Kopie ist Teil einer Kopienserie, die während seines zweiten Aufenthaltes in Spanien, 1628/29, entstand. Es handelt sich bei den Vorbildern um vielgerühmte Meisterwerke, und Tizians Europaraub findet sich als Zitat selbst wiederum in Diego Velázquez', den Madrider Hof und die Malerei als solche reflektierendem Gemälde der Hilanderas von 1657, also bei dem Künstler, mit welchem Rubens während seines zweiten Madrider Aufenthaltes in Fragen der Ausstattung der Staatsappartements zu tun hatte. Das Rubensgemälde heute im Museo del Prado, Madrid, Tizians Raub der Europa im Isabella Stewart Gardner Museum in Boston.
} 
repetierte Tradition des Fürstenmalers einschrieb, die insbesondere mit Tizian und Philipp II. sowie Karl V. die Alexander-Apelles-Konfiguration in Madrid neu inszenierte ${ }^{2}$.

Die als Aktualisierung des Vorgefundenen beschreibbare Bezüglichkeit solchen bildkünstlerischen Handelns bedeutet ein Selbstverständnis, das den Künstler als Bezugsgröße von Geschichte und als epochemachendes, selbstbewusstes Individuum behauptet, als doppelte Gerichtetheit eines historischen Bewusstseins. Es ist die damit geprägte Historizität einer Bildkunst, die in anhaltender Aufladung mit den zu emblematischen Bildern und Formeln „Europas“ geronnenen Meisterwerken die identitätsprägenden abendländischen Bildschöpfungen interpretierend weiterreicht. Rubens' Schöpfungen transformieren diese Vorbilder zugleich zur Vision eines verheißungsvollen, zukunftsgerichteten Kulturraums, der auf einer weit in die Geschichte ausgreifenden Selbstbesinnung fußt, gerade mit und durch den Dreißigjährigen $\mathrm{Krieg}^{3}$.

Der selbstbewusste Bedeutungsreichtum der Konnotationen „Europas“ im 17. Jahrhundert mag man auch der Rede vom Barock unterlegen, deren Implikationen als malerisches Signet und Korrelat im Bewusstsein um das Rubenssche Euvre aufscheinen. Mit welcher Malerei ließe sich das, was „Barock" auszudrücken versucht, besser benennen, als mit den Bildschöpfungen von Rubens, die in nahezu allen Gattungen als Platzhalter im abendländischen Bildgedächtnis operieren können? Die Bewegtheit des Barock ist in der Bewegung der Formen zugleich Bewegung der Affekte und Bewegung in der Zeit.

Solcher Vereinnahmungen sind viele, und mit einigem Grund hat man immer wieder betont, zu Rubens sei alles geschrieben worden. Doch es ist nicht an uns, sich von der eigenen Tradition und der durch diese Interpretationsgeschichten bestimmten, kulturellen Färbung des Bewusstseins zu verabschieden. Das Neudurchdenken ist besonders dann ständige Aufgabe der Kunstgeschichte, wenn die zahlreichen Mythen um den heute so präsenten Maler hartnäckig fortbestehen. Bei genauerem Hinsehen vermitteln sie ebenso ein Bild von der Selbstinszenierung des Künstlers wie eine Geschichte der Projektionen der Wissenschaftlergenerationen.

${ }^{2}$ So treffen wir bereits in den frühen Biographien von Rubens, etwa bei Sandrart, die rühmende Formel vom Apelles des Nordens an. Auch für den Hofmaler Diego Velázquez, der in seinem Gemälde der Meninas selbst wiederum die Rubensgemälde zitiert, wurde die Bezeichnung ,nuestro gran Tiziano" von seinem Biographen Palomino rühmend eingefuhrt.

${ }^{3}$ Zum politischen Kontext im Zusammenhang der Künste vgl. anläßlich der Europaratsausstellung Münster und Osnabrück 1989: 1648 - Krieg und Frieden in Europa, hrsg. von Klaus Bußmann [u. a.], Münster 1998. Zu Rubens als Kopist vgl. Die Ausstellung München, Alte Pinakothek: Rubens im Wettstreit mit Alten Meistern: Vorbild und Neuerfindung, hrsg. von den Bayerischen Staatsgemäldesammlungen, Ostfildern 2009. 
Es geht darum, die Relevanz der Künstlerreise in der Frühen Neuzeit für das immer andere Bild Europas aufzuzeigen und dabei der fortwährenden Horizontverschiebung Rechnung zu tragen, in die sich das Rubensbild einschreibt. Besonders vor der Frage nach der Mobilität des Künstlers im 17. Jahrhundert modelliert sich der Kontext, der die Ausbildung einer Künstlerpersönlichkeit wie der Rubens' erklären hilft. Notwendigkeit und anhaltender Drang zu überarbeiten, umzuformulieren und zu neuen Perspektiven zu gelangen ist auch dessen künstlerischer Arbeit eigen. Das Reisen bedingt diese Perspektivverschiebungen mit. Neben den Kopien zwischen Nachahmung und Neumodellierung ist uns eine Vielzahl von Zeichnungen seiner Vorgänger erhalten, die der Flame sammelte, teils respektlos überging und in seinem Sinn remodellierte.

Die Frage nach dem reisenden Künstler kann hier - angesichts fehlender Quellen - nur die Frage nach den Orten, nach den bereisten Städten und ihren soziokulturellen Kontexten sein. Allenfalls das Bewegungsprofil des Künstlers mag Aufschluss geben, etwa über seine Vernetzung im Geflecht des höfischen Austauschs einerseits und die Organisationsform von Atelier und reisendem Meister andererseits. Gleichwohl ist die Causa Rubens für eine Aufklärung über das, was die Künstlerreise im frühen 17. Jahrhundert sein kann, in besonderer Weise geeignet, doch bürdet sie aus kunsthistorischer Sicht zugleich die Last auf, in der Bildproduktion die Konsequenzen der erstaunlich hohen Mobilität zu entdecken ${ }^{4}$. Nach Themen, Bilderfindung und stilistischen Merkmalen trägt das Euvre in beispielloser Weise der Auseinandersetzung und Einbindung des Schaffens in die politisch-historischen Gegebenheiten der Zeit Rechnung. Es ist wesentlich durch eine insgesamt, insbesondere durch den Krieg bestimmte, hohe Mobilität gekennzeichnet. Kaum ein Bild des Malers, das nicht im Kontext der europäischen Machtpolitik, der Gegenreformation oder der sozialen Selbstpositionierung der Künstlerpersönlichkeit argumentiert; eine Technik, die von Flexibilität und Mobilität im Wortsinn spricht.

\section{Popularität verpflichtet}

Die Liste der großen Rubenssammlungen (London, Paris, Wien, München, Madrid usf.) bezeugt die globale, historische Wirkmacht des Flamen. Diese Diffusion seiner Bilder ist letztlich durch die Strategie des durch Europa

Synchronisiert man die Reisen des Malers mit den von der Kunstgeschichte geltend gemachten Stilphasen Rubens' zwischen frühem Klassizismus und den luziden, späten Landschaften, so lässt sich andeuten, wie sehr die sich aus dem Reisen ergebende Erfahrung des Fremden und der Künstlervorbilder als Katalysator ständigen Fortschreitens gewirkt haben mag. 
reisenden, seinen Ruhm strategisch mehrenden Künstlers intendiert. Voraussetzung der Massenrezeption ist hier wie da die Wiedererkennbarkeit, diejenige von eingängiger Melodie und Einlösung anschaulicher Erwartung, als funktionierende Projektionsfläche eigener Sehnsüchte. Damit liegt zugleich ein Motiv vor, welches immer wieder als Charakteristikum Rubensschen Schaffens herausgestellt wurde: die lebendige, sinnlich affizierende Veranschaulichung hoffnungsvoller, optimistischer Zukunftserwartung. Die Manier von Rubens, deren Heranbildung und Fortentwicklung als Markenzeichen ist Resultat der bildpraktischen Erfahrungen, die nur über das Reisen zu gewinnen waren. Die Werke in ihrem Kontext zu verstehen, versetzt uns erst in die Lage, beispielsweise die Allegorien des Malers nicht immer wieder als Antikriegsbilder im Sinn eines modernen Pazifismus mißzuverstehen. Dessen ungeachtet arbeiten wir auf ungleichem, beliebigem oder verwässertem Niveau das, was uns hier interessieren soll, nach: mit beschleunigtem und kontextenthobenem Reisen, besonders an die alten Orte höfischer Machtkonzentrationen. Und auch der Ausstellungsbetrieb imitiert als Abklatsch den Kontext, in welchem die Bilder einst entstanden sind, auch wenn die reiche Bilderverschickung nichts anderes meint als der nun nicht mehr höfische, sondern Massenmentalitäten manipulierende Geschenkverkehr bildhafter Programme. Was bedeutet es also für das 17. Jahrhundert, wenn ein Künstler reist? In welchem historischen Gefüge und mit welchem Gepäck unternimmt er die Reisen, und was meint dies für unsere Wahrnehmung seiner Bilder?

\section{Die genüssliche Verführung und die Faktizität der Geschichte - Rezeptionsgeschichten}

„In Burckhardts schriftstellerischem Werk ist dies wohl die Stelle, wo sich am deutlichsten zeigt, daß der 'Genuß der Kunstwerke' durchaus nicht nur den, ästhetischen Genuß' der Formen, Farben und allenfalls noch bestimmter Bildthemata meint, sondern wesentlich von der Erinnerung an den Künstler und von der Vergegenwärtigung des Entstehungsprozesses der Kunstwerke gespeist wird" 5 .

Wilhelm Schlinks Analyse der Burckhardtschen Rubensexkurse zielt auf das Selbstverständnis der Kunstgeschichte als Disziplin: „In den Erinnerungen aus Rubens ergreift Burckhardt jedes sich bietende Stichwort, um sich mit der Rolle des Künstlers in seiner eigenen Zeit - der Zeit der Industrialisierung und der Salons - auseinanderzusetzen. Dieser Moderne gilt das Gegenbild der glückhaften künstlerischen Existenz eines Rubens, ihr gilt es zu zeigen,

${ }^{5}$ Vgl. Wilhelm SCHLINK, Jacob Burckhardt über den 'Genuß der Kunstwerke' in: Trierer Beiträge - Aus Forschung und Lehre an der Universität Trier 11 (1982), S. 48 ff. 
unter welchen gesellschaftlichen und kulturellen Prämissen wahres Künstlertum und wahrer Kunstgenuß möglich waren, - woran es liegt, wenn der ruhige Kunstgenuß von einst zur hektischen Kunsterwartung deformiert ist“". Burckhardts Kontrastierung von Rubens mit der Charakteristik seiner Zeit, als ,fruchtbares Wettrennen in Kunst und Wissenschaft“, macht deutlich, daß es nicht um die moderne Vorstellung des Künstlers gehen kann, der in Opposition zum Leben und zur Gesellschaft seiner Zeit dieses zu durchbrechen und jener zu widersprechen hat. Gerade der Einklang von Leben und Werk ermöglichte Rubens, aus dem Vollen zu schöpfen. Wie Schlink zeigte, ist das bei Burckhardt keine sentimentalisch rückwärtsgewandte Sehnsucht, sondern der Drang, die Bedingungen der Kunst (und ihrer zeitgenössischen Produktion) mithilfe historischer Kenntnis und Vergewisserung freizulegen.

Burckhardts wache Unvoreingenommenheit, sein Weitblick als Historiker ist beispielhaft, aber auch unabdingbar, wenn es darum geht, den zeitbedingten Konstruktionen der Geschichtsschreibungen nicht aufzusitzen. So erhielt die mit dem 19. Jahrhundert vorbereitete Einmündung in die Erzählung der Nationalgeschichten mit der Abspaltung Belgiens vom Königreich der Niederlande einen Schub, der die Künstler in den Kontext neuer Identitätsstiftungen einstellte. Der die nationale Reaktion herausfordernde Schock der Abtrennung bedeutete für Rubens, zuvor Leitfigur der gesamten Niederlande, zusammen mit Rembrandt als neu implementiertes, je nationales Emblem flämischer bzw. holländischer Malerei instrumentalisiert zu werden. Dieser ideologischen Auseinandersetzung im Kleinen stehen die Projektionen zur Seite, die den Maler in die Auseinandersetzung um die europäische Kulturhegemonie bis weit in die Moderne hereinzog. Als Karl Maria Swoboda - mit der Selbstpositionierung während seiner Prager Professur ab 1934 politisch durchaus belastet, gleichwohl Nachfolger Sedlmayrs auf dem Wiener Lehrstuhl - in seinem ersten Aufsatz nach Kriegsende unter dem Titel Rubens und Europa das nördliche Europa mit der mediterranen Kunstauffassung konfrontierte, geriet die Wölfflinsche Opposition von Barock und Klassizismus erneut in den Strudel grundsätzlicher Bedeutungsstiftung ${ }^{6}$. Es ging dem Verfasser um die sich ablösenden Weltanschauungen und Rubens als Verkörperung des Barock, letztlich - mit echter oder vorgeschützter Naivität, jedenfalls mit ignorantem Kalkül - um die Geschichte dieses Antagonismus seit den Ursprüngen der Menschheit. Hiervon hat sich einiges im Bewußtsein der Kunstgeschichte, aber auch der allgemeinen, populären Vorstellungen über Rubens und besonders das Körperideal seines Bildpersonals erhalten. Das

6

${ }^{6}$ Auch im unveröffentlichten Aufsatz Alteuropa - Europa von 1944/45 führt er noch die geschichtlichen „Triebkräfte und Lebensformen“ auf die vorgeschichtlichen Konstanten Rasse, Körper- sowie Charaktertypik und Geschlechterpolarität zurück, Themen, die sich angesichts Rubensscher Bilder aufdrängen mögen. Karl Maria SWOBODA, Rubens und Europa, in: Kunst und Geschichte - Vorträge und Aufsätze, Graz [u. a.] 1969. 
allein mag Anlass genug für ein neuerliches Durchdenken sein. Der seit der Antike überlieferte Topos einer Opposition nordischer und mediterraner Kunst- und Anschauungswelten dient bis heute als Orientierungsinstanz, wenn es um die Erklärung scheinbar unvereinbarer Muster geht. Wenn Rubens solche Trennung in mehrfachem Sinn durchkreuzt, die unscharf abgegrenzten Hemisphären in einer fruchtbaren Konfrontation zu seiner internationalen Manier ausformt, die zugleich nicht in den Eigenarten des einen oder anderen aufgeht, das Typische ebenso einschließt wie das den Vorbildern Abgeschaute, dann ist das einer Mobilität zu verdanken, die räumlich, geistig wie praktisch zwar einmalig, aber für die frühe Neuzeit Europas ebenso sprechend ist. Wie Burckhardt es formulierte, hilft uns hier nur die Kenntnis der Fakten. Denn gerade mit der schon im Frühwerk auszumachenden, dezidiert „europäischen“ Verflechtung seines EEuvres lässt sich Aufklärung bringen, eine Kenntnis der Fakten, die es ermöglicht, den historisch eingeübten oder kommoden Einordnungen zu entgehen. Rubens im Kontext seiner Zeit zu sehen bedeutet dann auch, die Besonderheiten der frühneuzeitlichen „Schwellenzeit“, ob als Krise oder Aufbruch gelesen, zu berücksichtigen.

\section{Antwerpen}

Man mag die Ereignisse um die Flucht des reformierten Jan Rubens - Advokat und Berater der Anna von Sachsen, Gemahlin Wilhelm von Oraniens nach Köln und dann Siegen als frühe Vertrautheit des Peter Paul mit Fragen der Religionsunruhen lesen. Nach dem Tod des Vaters in Köln 1587 und dem Wegzug der Familie nach Antwerpen besuchte der junge Rubens die Lateinschule, die den Grund seiner klassischen Bildung gelegt haben wird ${ }^{7}$. Mit dreizehn Jahren, nach einer Zeit als Page der Comtesse de Lalaing in Oudenaarde unweit von $\mathrm{Brüssel}^{8}$, nahm er 1590 die Ausbildung beim Land-

${ }^{7}$ Es handelt sich um die Schule von Romulus Verdonck, wo er bis 1590 lernte.

${ }^{8}$ Über die Dauer dieser Anstellung herrscht in der Rubensliteratur Uneinigkeit und Verwirrung. Es macht allerdings kaum Sinn und es gibt nach den Quellen keinen Grund, die Aufgaben des jungen Rubens im Haushalt der Gräfin Lalaing auf wenige Monate zu beschränken. Ausfuhrlicher hat zuletzt Nils Büttner die etwas komplexe Situation beleuchtet. Marguerite de Ligne-Arenberg (1552-1611) war Witwe des Comte Philippe de Lalaing, Baron de Escornaix (1537-1582) (die gleichnamige Tochter, Marguerite Comtesse de Lalaing, Baronne d'Escornaix [1574-1650] war verheiratet mit Florent Comte de Berlaymont, Gouverneur und Capitaine général de Luxembourg). Mit der Heirat vereinigten sich zwei der nobelsten Familien der Niederlande. Philippe de Lalaing, zunächst auf Seiten der Aufständischen, wechselte die Fronten und wurde unter den Habsburgern Gouverneur des Hennegau. Büttner vermutet (da es sich hier um eine der bedeutendsten Kunstsammlungen des Nordens, mit zahlreichen Antiken und ca. 2000 Gemälden handelte), dass Rubens hier früh im höfischen Besuch und Austausch geschult worden war. $\mathrm{Zu}$ den zahlreichen Verflechtungen in diesem Patronagesystem und der frühen Kenntnis des höfischen 
schaftsmaler Tobias Verhaecht, dann beim Figurenmaler Adam van Noort auf, unter dessen Anleitung er vier Jahre lernte ${ }^{9}$. Den bedeutsamsten Lehrer wird man in Otto van Veen sehen müssen, in dessen Atelier er 1594 eintrat. Als einer der erfolgreichsten Maler und Lehrer der Zeit hatte van Veen fünf Jahre in Italien, hauptsächlich in Rom, verbracht, wo er als Schüler Federico Zuccaris sich mit Theorie und Praxis der italienischen Kunst vertraut gemacht hatte. Rubens wurde als Maler durch die Antwerpener Gilde 1598 anerkannt ${ }^{10}$ und verblieb dann bis 1600 in van Veens Atelier. Hier wird er sich vor allem nach Stichen, etwa Marc Antonio Raimondis, mit der italienischen Kunstproduktion auseinandergesetzt haben. Nach zwei Jahren als Freimeister der Gilde brach er nach Italien auf, um erst acht Jahre später, nun als Hofmaler des Brüsseler Regentenpaares zurückzukehren, mit einem Status, der ihn zum ersten Maler seines Heimatlandes deklarierte.

Das Mit-, Neben- und Beieinander, die Melange der Sprach- und Kulturgruppen und die hierdurch scheinbar unvermeidlichen Gräben, wie sie heute noch Flandern, Wallonien und Ostbelgien durchziehen, kann für das frühe 17. Jahrhundert durchaus unter umgekehrtem Vorzeichen, als Vorteil einer Internationalität, gelesen werden, die Antwerpen zu einem der wichtigen Handels- und Kunstzentren machte. Die einst burgundische Stadt fiel 1477 an Habsburg, und trotz der Reformation 1556 entwickelte sie sich zu einer der reichsten Handelsstädte Europas, bedroht durch die folgenden Konflikte, besonders nach der habsburgischen Rückeroberung durch Alessandro Farnese 1585 und die Ausweisung der Protestanten. Trotzdem kann kaum ein lebendigerer Ort gedacht werden, von welchem aus eine internationale Malerei abseits nationaler Festlegung erfolgreich sein konnte ${ }^{11}$. Von hier aus machte sich der junge Maler nach Italien auf. $\mathrm{Ob}$ die Reise vorab mit Vereinbarungen zwischen den Höfen Brüssel und Mantua geplant war, lassen die Quellen nicht erkennen.

Man ist zunächst versucht, die Italienreise des Malers aus der romantisch verklärten Sicht des in die Ferne aufbrechenden jungen Künstlers zu lesen. Das Ungenügen an der heimischen Kunstwelt, mit ihrer noch lebendigen

Zeremoniells, eines Hofes, an welchem Französisch gesprochen wurde und zur Teilnahme von Rubens am höfischen Ausbildungssystem (Zeichnen, Sicherheit im Auftreten) vgl. Nils BÜTTNER, Rubens, München 2007, S. 31.

${ }^{9}$ Es fehlen uns letztlich die Dokumente, um den genauen Beginn und die Details seiner Lehrzeit zu kennen. Der Bericht seines Neffen erweist sich als unvollständig.

${ }^{10} \mathrm{Vgl}$. P.H. Rombouts [u. a.], De Liggeren en andere historische Archieven der Antwerpsche Sint Lukasgilde, 2 Bde., Repr. Amsterdam 1961, Bd. I, S. 401: „Peeter Rubbens, Vrymeester, schilder".

Antwerpen war neben den oberitalienischen Städten eines der großen Zentren der europäischen Wirtschaft. 1477 unter burgundische Herrschaft geraten, wurden die Territorien von den Habsburgern beerbt, zunächst vom spanischen, dann vom österreichischen Zweig. 1794 wurde es vom revolutionären Frankreich annektiert, um 1815, auf dem Wiener Kongress, den Niederlanden zugesprochen zu werden. 
Tradition des Antwerpener Manierismus, mag hier sicher eine Rolle gespielt haben, doch mit dem beginnenden 17. Jahrhundert ist die Italienfahrt bereits obligatorischer Bestandteil der Malerausbildung. Rubens folgt damit dem Vorbild seines Lehrers und der Generation der Italienfahrer. Die Regeln der Zunft sahen zudem ganz einfach vor, im Kontext der Entschärfung von Konkurrenzen auf Wanderschaft zu gehen. Angesichts der wohlwollenden und schnellen Aufnahme des Malers in Italien kommt man jedoch nicht umhin, die Reise nicht allein durch die Notwendigkeiten der Kunstbildung bestimmt zu sehen. Auch das Interesse des höfischen Austauschs wird hier maßgeblich gewesen sein. Mit Bezug auf das Gesundheitszeugnis des Antwerpener Magistrats, das jedem Reisenden auszustellen war, erkennt Nils Büttner in dem Passus ,negociorum suorum causa“ Anzeichen dafür, es habe sich von Anbeginn an um eine „Geschäftsreise“ gehandelt ${ }^{12}$.

Zweifellos waren die Arbeitsmöglichkeiten, insbesondere an den zahlreichen oberitalienischen Höfen und in Rom, gegeben. Mit Poussin, Claude Lorrain oder Jan van der Straet seien nur einige der in Italien erfolgreichsten Künstler genannt. Und ohne den Sehnsuchtsfaktor ausschließen zu müssen: Italien war in den Niederlanden seit den Pionieren des 16. Jahrhunderts, den sogenannten Antwerpener Romanisten wie Martin van Heemskerck, aus einer Künstlervita kaum wegzudenken. Jan Breughel d. Ä, mit dem Rubens dann zusammenarbeiten sollte, kehrte erst 1596 mit zahlreichen Bildern im Gepäck aus Italien zurück. Bis heute haben sich Reste dieser Verbindung in institutionalisierter Form, sei es für die Kunstgeschichte oder die Künstlerausbildung, mit den Instituten in Florenz und Rom, mit der Akademie Villa Massimo oder der Villa Medici in Rom erhalten. Die Italienreise um 1600 hatte für einen flämischen Maler also keinerlei Exotik mehr, wenngleich die widrigen Bedingungen des Reisens das Abenteuer nicht ausschlossen. In diesen Fußstapfen tritt Rubens am 9. Mai 1600 seine Reise an, sicher durch Van Veen ermuntert und zweifellos nicht ohne Empfehlungsschreiben für den ein oder anderen Kunstpatron.

\section{Italien}

Mit der Veröffentlichung der Archivalien des Mantuaner Archivs legte Armand Baschet in den sechziger Jahren des 19. Jahrhunderts den Grundstein für die Erforschung der Rubensaufenthalte in Italien ${ }^{13}$. Im Mai 1600 erhielt Rubens in Antwerpen seine Reisedokumente. Über die genaue Route ist we-

\footnotetext{
12 Vgl. BÜTTNER, Rubens (wie Anm. 8), S. 16, der von einer Beschättigung von Rubens durch den Hof bereits vor seiner Reise nach Italien ausgeht.

${ }^{13}$ Eine erste frühe Übersicht gibt Rudolf OLDENBOURG, Rubens in Italien, in: Jahrbuch der königlich Preussischen Kunstsammlungen 37 (1916), S. 262-286.
} 
nig bekannt, und so wissen wir nicht, ob Rubens über Frankreich reiste und so z. B. Fontainebleau und die von Primaticco ausgeführte Galerie Henri II sehen konnte. Zwei Monate später, im Juli erreichte er Venedig. Von den Zwischenstationen ist uns nichts überliefert, was eine Reise über die Reichsterritorien wahrscheinlich macht, die Reise über Lyon aber nicht ausschließt. Wie sehr Rubens von der venezianischen Malerei beeindruckt wurde, läßt sich nur anhand seiner Bilder nachvollziehen. Tizians Ecce Homo ${ }^{14}$, ein Werk für einen erfolgreichen flämischen Kaufmann in Venedig, seine Dornenkrönung hinterlässt Spuren in Rubens' Geißelung Christi von 1602 (Nizza, Kathedrale $)^{15}$, und noch in die Wiederauferstehung für die Antwerpener Kathedrale von $1611 / 12^{16}$ scheint sich Tizians Einfluss übertragen zu haben.

Die Beantwortung der Frage, wie Rubens zur Anstellung in Mantua kam, bleibt auf Vermutungen und die wenigen Dokumente verwiesen. Möglich, daß sein Lehrer Otto van Veen - er war selbst Hofmaler für den Statthalter der Niederlande, Alessandro Farnese, und sicher auch für Albrecht VII. von Österreich und seine Gemahlin Isabella ${ }^{17}$ tätig, Vincenzo hatte beide 1599 besucht -, den jungen Rubens empfohlen hatte. Ob Vincenzo Gonzaga tatsächlich auf der dringenden Suche nach einem Hofmaler war, sei dahingestellt; sein Zahlungsverhalten und das Laissez-faire im Blick auf die freie Reisetätigkeit des Malers während seiner Mantuaner Bestallung lassen ebenso gut das Gegenteil vermuten. Doch darf man getrost die enge Bindung, ja die Abhängigkeiten Vincenzos in Anschlag bringen, da das Haus Gonzaga durch die Verleihung der Herzogswürde durch Karl V. seinen Rang erhalten hatte $^{18}$.

14

Heute Wien, Kunsthistorisches Museum. Tizian hatte das Werk 1543 für Giovanni d'Anna, den Sohn des in Venedig installierten flämischen Kaufmanns Martin van der Hanna, fertig gestellt. 1620 vom englischen Gesandten Sir Henry Wotton für George Villiers, Duke of Buckingham erworben, von welchem das Gemälde für den astronomischen Preis von 7000 Pfund an Thomas, Earl of Arundel ging, gelangte das Werk 1648 beim Verkauf der Sammlung durch die Nachkommen schließlich in die Sammlung des ErzherZogs Leopold.

${ }_{16}^{15}$ Notre Dame du Puy, die Kathedrale von Grasse.

16 1611/12 für Martina Plantin, die Witwe von Jan Moretus, Schwiegersohn des 1610 verstorbenen Antwerpener Druckers gemalt.

${ }_{17}$ Die habsburgische Heiratspolitik sah die Tochter Philipps II., Isabella Clara Eugenia, bereits in ihrem zweiten Lebensjahr als Gemahlin für Rudolf II. vor, den Sohn Maximilians II. von Österreich, mit dem sie dann zwanzig Jahre lang verlobt sein würde. Die Verbindung der Infantin mit dem als Neffe des Spanischen Königs ebenfalls am Hof Philipps II. von Spanien erzogenen Erzherzogs Albrecht VII. von Österreich wurde mit der Übertragung der spanischen Niederlande an das Paar gekrönt. Isabella erhielt Flandern, Artois, Hennegau, Brabant, Cambrai, Limburg und Luxemburg. Nach dem Tode ihres Gemahls 1621 regierte sie dann als Statthalterin weiter.

${ }^{18}$ Vincenzo Gonzaga hielt sich anläßlich der Hochzeitsfeierlichkeiten von Albrecht und Isabella, knapp zwei Jahre zuvor, in den Niederlanden auf. Für dessen Einzug spielte das Atelier van Veens eine wichtige Rolle. 
Kurz nach seiner Ankunft in Venedig - es wurde ihm von einem Höfling des Herzogs von Mantua eine Anstellung angetragen - traf Vincenzo selbst in Venedig ein, und Rubens wird ihn dann an den Mantuaner Hof begleitet haben $^{19}$. Dort arbeitete bereits sein Landsmann Frans Pourbus (1600-1609), zu dem Rubens auch nach der Rückkehr nach Antwerpen Kontakt halten wird. Mit Claudio Monteverdi, der von 1590 bis 1612 am Mantuaner Hof bestallt war und seinen Fürsten nach Flandern und Ungarn begleitete, mit der zeitweiligen Anwesenheit Torquato Tassos war Vincenzos Hofhaltung auf internationalem Parkett durchaus konkurrenzfähig ${ }^{20}$. Doch muss unklar bleiben, ob es sich bei den Freiheiten Rubens', die ihm erlaubten, in Italien erstaunlich ungebunden umherzureisen, um die Großmut seines Herrn oder die pekuniäre Zwangslage des Mantuaner Haushalts handelte. Die Quellen belegen Rubens' Aufenthalte in Florenz, Genua, Padua, Verona, Treviso, Parma, Bologna und Mailand. Während der Mantuaner Zeit des Malers sind zwei längere Perioden in Rom sowie zehn Monate in Spanien vom März 1603 bis zum Frühjahr 1604 von besonderer Bedeutung.

In Mantua selbst waren es vor allem die Arbeiten des Raffaelschülers Giulio Romano, der als Hofmaler des Herzogs dessen Paläste mit aufwendigen Fresken ausgestattet hatte. Zweifellos galt es, sich zu Beginn des Italienaufenthalts als fortschrittlicher Künstler auf der Höhe der Zeit zu zeigen. In diesem Kontext höchster Präsenz der unantastbaren Großmeister der Renaissance hätte nichts kontraproduktiver sein können, als sich hier anzugleichen. Und so zeigte sich schon hier die Fähigkeit von Rubens, die zahlreichen Vorbilder und Exempla zu studieren, zu dokumentieren und diese in eigenen Werken zu transformieren. Die vielen Zeichnungen und Studien, etwa nach den Fresken der Götter und Giganten Romanos im Palazzo del Te, selbst die Stukkaturen Primaticcios der Sala degli Stucchi, geben Zeugnis dieser Aemulatio ${ }^{21}$.

Bereits im Oktober 1600 wurde Rubens nach Florenz gesandt, um dort seine Aufgaben als Mitglied der Hochzeitsdelegation für die Heirat der Maria de Medici mit Heinrich IV. wahrzunehmen ${ }^{22}$. Von der Kenntnis Michelangelos und der Medici Kapelle in San Lorenzo muß man ausgehen, wenngleich sich hier keine zweifelsfrei datierbaren Zeichnungen erhalten haben. Doch für

${ }^{19}$ Vgl. hierzu die Akten im Archivio di Stato, Venedig, Indice dei Cerimoniali, Vol. 111, 1600 .

${ }^{20} \mathrm{Zu}$ Rubens und Monteverdi vgl. Hans OST, Rubens und Monteverdi in Mantua - Zur Götterversammlung der Prager Burg, in: Rubens passioni: Kultur der Leidenschaften im Barock, hrsg. von Ulrich Heinen [u. a.], Göttingen 2001, S. 110-158.

${ }^{21} \mathrm{Zu}$ Rubens' Mantuaner Zeit und zu Giulio Romano als Vorbild vgl. Michael JAFFé, Rubens and Giulio Romano at Mantua, in: The Art Bulletin 40 (1958), S. 325-329.

${ }^{22}$ Mütterlicherseits selbst aus dem Hause Habsburg, betrieb sie das Ende der antihabsburgischen Politik der französischen Krone und versuchte über die Verheiratung ihrer Töchter mit Spanien und England zu einer Stabilisierung der Machtverhältnisse zu gelangen. 
jeden Italienreisenden der Zeit war Rom das erste Ziel, sei es für die Heerscharen der Pilger oder die Künstler, die in den Palästen der Kunstförderer und den zahlreichen Sammlungen ihren Studien nachgingen.

\section{Rom I - Furia del penello}

Rubens traf im Juli 1601 in Rom ein, wo er sechs Monate verbrachte. Er erreichte die Stadt mit einem Empfehlungsbrief seines Mantuaner Dienstherrn an den Kardinal Montalto, den Neffen des Felice Peretti di Montalto, der als Papst Sixtus V. 1590 im Amt verstorben war. Rom bot nicht nur Gelegenheit, die aktuelle Künstlergeneration zu treffen und ihre Werke zu studieren, allen voran Caravaggio und Annibale Carracci, sondern auch die großen Monumente der Renaissance, Michelangelos Sixtina, Raffaels Stanzen im Vatikan sowie die Originale der reichen Antikensammlungen. Montalto residierte in der Villa Medici und wird dem Maler den Zutritt zu manchen Privatsammlungen erschlossen haben. Im Euvre des Flamen sind so zahlreiche Zeichnungen erhalten, die von seinem intensiven Studium zeugen: nach dem Laokoon im Cortile Belvedere, dem Herkules Farnese im Hof des Palazzo Farnese und dem sogenannten Sterbenden Seneca, dem afrikanischen Fischer der Sammlung des Scipione Borghese. Aus den vielen Studien spricht die Faszination am anatomischen Detail. Es ging Rubens besonders um die Plastizität der Exempla und das Agieren der Figuren im Raum, eine Qualität, die nur mit dem vollplastischen Original zu erfassen war und die dann immer wieder in den Gemälden des Malers reflektiert werden wird ${ }^{23}$. Der Maler erarbeitete sich so einen Kanon der vorbildlichen Werke der Antike, fast sämtlicher bekannter Opera Nobilia wie der Herkules und der Torso Belvedere, die Laokoongruppe und der sog. Spinario ${ }^{24}$.

Neben aller Antikenbegeisterung führte der etablierte Kanon der Renaissance-Schulen, ihrer Topographie (Rom, Toskana, Venedig, Lombardei) und ihre herausragenden Vertreter (Leonardo, Michelangelo, Tizian, Parmiganino) zu einem überreichen Tableau, das individuelle Lösungen nahezu herausforderte. Es galt aufzufallen. Und Rubens trat in die Lücke, die weder die Italie-

${ }^{23}$ Man muß wohl die Auseinandersetzung mit der Bildhauerkunst der Antike als Basis nicht nur für die Rubenssche Figurerfindung verstehen. Über das Theorem der Verlebendigung der Skulptur, das Rubens theoretisch wie in den konkreten Bildlösungen thematisiert, hinaus vermittelt das Studium der antiken Skulptur die gesamte Auffassung einer malerischen, bildplastischen Gestaltung. Hiermit beeinflusste Rubens nicht zuletzt die flämische Bildhauerei, etwa mit Blick auf die Werke von Hans van Mildert oder Jan und Andries de Nole. Er wirkt damit auf die Generation, die den flämischen Frühbarock in der Skulptur mitbestimmte. Vgl. zu dieser Frage Werner KITLITSCHKA, Rubens und die Bildhauerei, Wien 1963.

${ }^{24}$ Zeichnung im British Museum, 1605-8. 
ner noch die Flamen oder gar Franzosen auszufüllen imstande waren, etwa, wenn er im durch die Generation Caravaggios durcheinander gewirbelten Kunstmarkt der Stadt im Portrait reüssierte und gegen jede Spezialisierung sich allen Gattungen und Formaten gegenüber aufgeschlossen zeigte ${ }^{25}$. Wurden unter dem sittenstrengen Sixtus antike Kunstdenkmäler zerstört und durch „christliche" ersetzt, bedingte der nunmehr vermehrte Bedarf an Gemälden, nicht zuletzt durch die gegenreformatorische Programmatik und Kunstpolitik gesteigert, eine Produktionssteigerung, die eine Furia del pennello zur Entfaltung brachte, die es vermochte, dem Bedarf an Fresken und Tafelbildern gerecht zu werden ${ }^{26}$.

Mit den Jahren seines Italienaufenthaltes nahm Rubens teil an den für die Kunstgeschichte entscheidenden Neuerungen, die mit Bildpraxis, Lehre und kunsttheoretischen Einwänden eine Überwindung des Manierismus beförderten. War Rubens in Antwerpen mit Vorgaben seines Lehrers noch den Lösungen eines Antwerpener Manierismus gefolgt, so erlebte er nun die Betriebsamkeit eines Aufbruchs, der Strategien individueller Sichtbarkeit erforderlich machte. Es war die Generation der Maler, kunsthistorisch seit Denis Mahon unter dem Prädikat der Seicentomalerei (ca. 1580-1630) zusammengefasst, die in der Rückbesinnung auf die großen Vorbilder der Renaissance sowie die Exempla der Antike zu einer neuen Natürlichkeit gelangen wollten. Die Prinzipien dieser Maler (Annibale Carrachi, Guido Renio, Domenichino u. a.) kommen am klarsten in der kunsttheoretischen Abhandlung des Giovanni Battista Agucchi zum Ausdruck ${ }^{27}$.

${ }^{25}$ Wie weitreichend des Malers Neugierde und Offenheit war, mögen die erstmals von Julius Held und Ludwig Burchard publizierten Zeichnungen aus dem Londonder Costume Book des British Museum nach persischen Miniaturen zeigen. Plädierten die frühen Autoren für eine Frühdatierung um 1600, stellt der Vergleich der Rubensskizzen mit den Miniaturen, wie sie am Hofe des persischen Shahs Abbas I. entstanden, die Frage, wie und wann Rubens solcherlei Vorlagen hatte sehen können. Der kommerzielle Austausch mit Persien, etwa durch den flämischen Händler Nicholas de Respaigne mit seinen Verbindungen nach Konstantinopel, setzt erst ab 1622 ein. Die beiden in persischen Diensten tätigen Edelmänner Sir Anthony und Sir Robert Sherley bereisten in den Jahren 1599 bis 1601 Italien und machten auch in Mantua Zwischenhalt. Ob hier oder während des ersten Botschafterpostens Sherleys (1608-13) am Hof in Madrid der Kontakt zu Rubens zustande kam, sei dahin gestellt. Spätestens mit den zwanziger Jahren finden die Beobachtungen der islamischen Kunst Eingang in die Malereien von Rubens, die mit ihren lebensgroßen Portraits in persischer, zumindest orientalischer Tracht unter dem Diktum des korrekten Kostüms Rembrandt antizipierten.

${ }^{26}$ Vgl. Nicola SUTHOR, «Il pennello artificioso». Zur Intelligenz der Pinselfuhrung, in: Instrumente in Kunst und Wissenschaft - Zur Architektonik kultureller Grenzen im 17. Jahrhundert, hrsg. von Helmar Schramm [u. a.], Berlin [u. a.] 2006, S. 114-136.

${ }^{27}$ Die Auswertung der reichen Archivalien, sein in vielen Fragmenten und Transkriptionen vorliegendes Skizzenbuch, aber auch das daraus extrahierte Traktat De Imitatione Statuarum sowie die Schrift Théorie de la figure humaine führen eindrucksvoll die gelehrte Kenntnis des Malers vor Augen, wenn es um die auf die Antike und Quintillian sich berufende Theorie, etwa eines Pietro Paolo Lomazzo oder Giovanni Battista Armenini ging. 
Wenn die Kenntnis, auch die der Variabilität der Meister Voraussetzung zur Schulung des eigenen Ingeniums ist, dann ist das Reisen und die Anschauung einer Vielzahl vorbildlicher Lösungen - gegen die Orientierung an der $\mathrm{Ma}$ niera eines Meisters - erste Erfordernis.

Wie man sich das vorzustellen hat, lässt sich sinnfällig an den Varianten studieren, die Rubens von den Vorbildern des immer wieder reproduzierten Herkules Farnese anfertigte ${ }^{28}$. Es sind die so durchdrungenen und dann als eigenständige Schöpfung anzusehenden Typen, die Rubens als Wiedergänger in zahlreichen Bildschöpfungen variiert und in einen gänzlich neuen Aktionsraum eintreten lässt.

Das Talent, neben seinen politischen Aufgaben, der Organisation der Reisen und der Tagwerke sich immer wieder durch zeichnendes, kopierendes oder gleich variierendes Arbeiten ein Archiv, eine Memoria aufzubauen, zeichnet den Maler als disziplinierten Uomo Universale aus. Dieses ständige Beobachten zeitigte eine eigene Sammlung. Im Fall der Zeichnung besteht diese aus eigenhändigen Notizen, ausgeführten großformatigen Zeichnungen, gesammelte Zeichnungen anderer Künstler sowie übergangenen Zeichnungen, die das Original mit der eigenen Manier überschreiben ${ }^{29}$. Noch PierreJean Mariette wird das im Katalog der Zeichnungen des Pariser Bankiers Crozat beschreiben: „Lorsque Rubens rencontroit des Desseins mediocres, ou mal conservés, d'après des gtans Maitres, il se plaisoit a les retoucher, \& y a mettre de l'intelligence, suivant ses principes. Il les transformoit ainsi de son propre goût, de sorte qu'a l'invention près, ces Dessines doivent entre regardés comme des productions de ce grand homme, ... “30.

Während der römischen Monate gelang es Rubens, zu einem seiner ersten großen, öffentlichen Aufträge zu kommen. Der Maler entsprach dem Wunsch Erzherzog Albrechts, ein Altarstück für Santa Groce in Gerusalemme auszu-

Zur Diskussion von Rubens' Äußerungen im Zusammenhang mit der zeitgenössischen Kunstauffassung vgl. den immer noch verbindlichen Aufsatz von Jeffrey M. MULLER, Ruben's Theory and Practice of the Imitation of Art, in: The Art Bulletin 64 (1982), S. 229247. Zu Studien des kreativen Prozesses bei Rubens anhand seines Skizzenbuches vgl. David JAFFÉ [u. a.], Ruben's „Pocketbook": An introduction to the Creative Process, in: Rubens - A Master in the Making, Ausst. London, National Gallery, 26. Oct. 2005-15 Jan. 2006, London 2005, S. 21-37. Ferner und jüngst: Tine MEGANCK, De la figure humaine chez Rubens: théorie, pratique et métaphysique, in: Rubens - L'atelier du génie, Ausst. Kat. Bruxelles, Musées Royaux des Beaux-Arts de Belgique, 14. Sept. 2007-27. Jan. 2008, Bruxelles 2007, S. 52-64.

${ }^{28}$ Eine gezeichnete Kopie, Mailand, Bibliotheca Ambrosiana; mehrere Varianten des Kopfes: London, Home House Trustees Society; Gemälde des Herkules Trimphans in Rotterdam, Museum Boymans-van Beuningen.

${ }^{29} \mathrm{Zu}$ Rubens als Sammler von Zeichnungen siehe Michael JAFFÉ, Rubens as a Collector of

Drawings, in: Master Drawings 4 (1966), S. 127-148 u. 188-203.
${ }^{30}$ Pierre-Jean MARIETTE, Description sommaire des desseins des grands maitres du cabinet de feu M. Crozat, Paris 1741, Écoles des Pays-Bas, no. 810. 
führen, dessen Titularkirche als Kardinal ${ }^{31}$. Dass die Wahl auf den Flamen fiel, muß als politisches Signal und als Ausdruck der römischen Präsenz des Brüsseler Hofes gelesen werden. Auch das mag dafür sprechen, dass Rubens die Reise aus Antwerpen als Künstler des Niederländischen Hofs antrat. Für den Maler selbst war es eine Gelegenheit, sich in der Konkurrenzsituation mit den wichtigsten Malern Roms messen und behaupten zu können ${ }^{32}$. Noch vor Ostern 1602, vor seinem Rückruf nach Mantua, vollendete er drei eindrucksvolle Altarblätter, die Geißelung Christi, eine Heilige Helena bei der Auffindung des wahren Kreuzes sowie die Aufrichtung des Kreuzes (heute als Kopie nach dem zerstörten Original in der Cathédrale de Grasse). Man mag hier den Einfluß Caravaggios erkennen, den er in San Luigi dei Francesi studiert hatte. Rubens' Gemälde künden zugleich von der Fähigkeit, schnell auf neue Anforderungen zu reagieren und seinen Personalstil zu wandeln. Sein schnelles Agieren verdeutlicht ebenso die politische Aufladung und die propagandistische Funktion seiner Malerei. Zurück in Mantua, schuf er dann Bilder für einen Aeneas-Zyklus, der den Sohn der Stadt, Vergil, feierte.

\section{Madrid}

Schon früh, 1603 wurde der erste Hofmaler Mantuas von seinem Fürsten nach Madrid gesandt, um dorthin Bilder zu überbringen. In diesem Austausch wird anhand von Bildern die Teilnahme auch an einer Kommunikationsform bekräftigt, die für das Verständnis der Gegenstände, das Lesen der Bilder zu einer mehr und mehr selbstreferentiellen Grammatik führt. Nicht zuletzt vermehrten sich textlich aufklärende Kommentare, Explicationes und Descriptiones im Laufe des 17. Jahrhunderts. Das hochentwickelte bildliche Verweissystem und die durch die höfischen Konkurrenzen beförderte Notwendigkeit, sich auf das aktuelle internationale Niveau zu bringen und sich dort zu halten, ist wesentlicher Antrieb für die Entfaltung der Künste. Je mehr der Künstler reiste und dabei auch originär künstlerische Erfahrung sammelte, umso mehr eignete er sich als Reisebegleiter der Fürsten, Gesandten und Adeligen; nicht nur wegen der Konsultationen, auch für die Dokumentation der Reise, die Verwertbarkeit im Sinn der Informationsgewinnung, der Schilderung des Zeremoniells, von Empfängen und auch der Kriegstaten.

31 Albrecht schrieb in dieser Angelegenheit an den Gesandten in Rom, Jean Richardot, dessen Sohn mit Rubens' Bruder Philipp in Italien auf Reisen war. Richardot erwirkte dann das Plazet für die Verlängerung des Aufenthaltes Rubens' in Rom durch seinen Mantuaner Dienstherrn.

${ }^{32}$ In der Würdigung von Rubens durch den Maler Giovanni Baglione von 1642, der Rubens eine „maniera buona Italiana" attestiert, mag dies zum Ausdruck kommen. 
Im März 1603 sandte man ihn nach Valladolid mit Geschenken für den König und seinen ersten Minister, den Herzog von Lerma. Die auf dem Transport zu See und über Land beschädigten Gemälde ersetzte er mit Werken aus eigener Hand, so z.B. das Gemälde von Demokrit und Heraklit (Valladolid, Museo Nacional de Escultura) ${ }^{33}$. Das am spanischen Hof entstandene Reiterportrait des Herzogs von Lerma (Madrid, Prado, 1603) kann wohl zu Recht als eins seiner ersten Meisterwerke betrachtet werden. Die knapp neun Monate in Spanien boten ihm Gelegenheit, die eindrucksvollste Sammlung von Werken Tizians zu studieren. Dabei mag auch das Bild des unabhängigen Messere Tizian, der zugleich erster Maler der habsburgischen Herrscher war, als heimliche Folie eines Malerfürsten wirksam geworden sein, dessen Bilder die Unnachahmlichkeit des Künstlerindividuums zum Ausdruck bringen konnten.

\section{Genua}

Rubens kehrt Anfang 1604 nach Italien zurück, zunächst mit dem Schiff nach Genua, von wo aus er im Folgejahr eine Reihe von Aufträgen erhielt. Zurück in Mantua widmete er sich der Ausgestaltung der Hauptkapelle der Jesuitenkirche mit drei Gemälden, einer Heiligen Dreifaltigkeit als Hauptaltar, der die Familie Gonzaga ins Zentrum rückt (nur Fragmente erhalten), einer Transfiguration (Musée des Beaux-Arts, Nancy) und einer Taufe (Antwerpen, Koninklijk Museum voor Schone Kunsten). Und auch hier argumentierte Rubens mit Bezugnahmen; das Gemälde des Hauptaltars mit seinem Verweis auf die flämische Tradition chromatisch reich abstufender Portraits, mit Engelsgestalten, die dem Repertoire Correggios viel verdanken. Die Transfiguration kann man als Gegenentwurf zu Raffaels berühmtem Gemälde im Vatikan lesen, mit einem an Tintoretto orientierten Kolorit und einer an Correggio gemahnenden Figurauffassung. Und die Taufe als Hommage an Michelangelo und die Antike mit einer Bildgestaltung, die mit dem Rekurs auf die Figurerfindung des Spinario im Kapitolinischen Museum sowie mit der Durchgestaltung des Nackten auf Michelangelos Schlacht von Cascina (diese nimmt selbst wiederum auf Leonardos Schlacht von Anghiari Bezug) zu einer neuartigen Synthese führt. Was hier zum Ausdruck gelangt, ist das selbstbewusste Statement des Künstlers, der die Großmeister Italiens, auf die sich nach dem

\footnotetext{
33

Rubens selbst gibt Auskunft über seine erste Mission, die ihn 1602 nach Madrid führte. Nach dem von seinem Stand abhängigen Rang wird er höchstens den Titel eines Sekretärs innegehabt haben. Der Brief, mit welchem er das Resultat seines Auftrags als Begleiter einer Geschenksendung am 17. Juli 1603 aus Valladolid nach Mantua sandte, berichtet, er habe dem Zeremoniell der Überreichung teils beigewohnt, teils dieses selbst durchgeführt, was sich wohl nur auf die Gemälde bezieht.
} 
Manierismus alle Augen richteten, studiert, in sich aufgenommen und anverwandelt hat, um so als Künstler gleichberechtigt an die Seite der Vorbilder zu treten.

Im Lauf des Jahres 1605 dann die Aufträge aus Genua, die Beschneidung Christi für Sant' Ambrogio et Andrea, bestellt vom Kanoniker und Bruder des Gonzaga-Bankiers Niccolò Pallavicini, den Rubens auf der Rückreise aus Madrid getroffen hatte, sowie eine Serie von Portraits der Genueser Aristokratie, wie das Portrait der Marchesa Brigida Spinola Doria (Washington, National Gallery of Art, Samuel H. Kress Collection). Während seines mehrmonatigen Aufenthalts wird es ihm vergleichsweise leicht gefallen sein, als Maler mit den großen Familien Genuas, den Spinola und Doria, Kontakte zu knüpfen. Die Verbindungen Mantuas mit Genua, aber auch die Kontakte der niederländischen Adelshäuser zu den Genueser Familien waren eng ${ }^{34}$.

\section{Rom II}

Im November des Jahres kehrte Rubens nach Rom zurück, wo er mit seinem älteren Bruder Philipp, der als Schüler des Humanisten und Philologen Justus Lipsius lernte und der nunmehr Bibliothekar des Kardinals Ascanio Colonna war, unweit der Piazza di Spagna wohnte ${ }^{35}$. Hier bewegte sich der Maler im Umkreis der Tedesci, etwa Adam Elsheimer, sowie den Mitgliedern der naturwissenschaftlich orientierten Academia dei Lincei, die mit Förderung des Papstes zu den innovativsten Orten des römischen Lebens gehörte. $\mathrm{Zu}$ den Gönnern der Akademie gehörte auch der antiquarisch interessierte Kardinal Cesare Baronio, der den Maler bei seinem folgenden römischen Auftrag unterstützte. Im Herbst noch erhielt er den wohl prestigiösesten Auftrag in Rom, der Rubens in unmittelbarste Konkurrenz zu den führenden römischen Künstlern setzte: das Altarbild für die Oratorianerkirche Santa Maria in Vallicella, eine der populärsten Kirchen der Stadt und Stammsitz des Ordens. Das Gemälde des Heiligen Gregor und der Flavia Domitilla wurde von der Kommission abgelehnt, und Rubens integrierte im Folgevorschlag das Fresko des 14. Jahrhunderts in die Konzeption, die mit drei Bildern (Die Jungfrau mit

341622 veröffentlichte Rubens dann ein Buch über die Palazzi di Genua, welches 1652 neu aufgelegt und in einer Bearbeitung von Cornelius Gurlitt im Jahre 1924 abermals vorgelegt wurde.

${ }^{35}$ Mit seinem Bruder Philipp, zwischen 1605 und 1607 Sekretär und Bibliothekar des Kardinals Ascanio Colonna, wohnte Rubens in der Strada della Croce unweit der Piazza di Spagna. Die Antikenkenntnis Philipps lässt sich in seinem Buch von 1607, das von Peter Paul illustriert wurde, studieren. Trotz wiederholter Aufforderungen seitens seines Auftraggebers Gonzaga kehrte Rubens nicht mehr nach Mantua zurück. Vgl. L. R. LIND, The Latin Life of Peter Paul Rubens by his Nephew Philip. A Translation, in: Art Quarterly 9 (1946), S. $37 \mathrm{ff}$. 
Kind flankiert von dem Heiligen Gregor, Maurus und Painianus sowie die Heiligen Domitilla, Nereus und Achilleus; alle in situ) der schwierigen Lichtregie des Kirchenraums Rechnung trug. Gerieten, als die neue Generation der Maler sich anschickte, die Sackgasse des Manierismus mit dem Zurück zu den Quellen der Antike und Hochrenaissance zu überwinden, Annibale Carraccis Werke bisweilen zu Bildern, die man leicht mit ihren Vorbildern verwechseln konnte, so vermochte Rubens zu einer Unverwechselbarkeit zu gelangen, zu einer bildlichen Marke, die bis heute ihre unverkennbare Wirkung entfaltet.

\section{Zurück in Antwerpen}

Von der Krankheit seiner Mutter in Kenntnis gesetzt, kehrte Rubens im Oktober 1608 aus Italien nach Antwerpen zurück. Er traf zu einem Zeitpunkt ein, zu dem sich mit der Unterzeichnung des Waffenstillstandes mit Spanien (9. April 1609) Optimismus und Aufbruchsstimmung verbreiteten ${ }^{36}$. Die daraus resultierende Auftragsmehrung für Kirchendekorationen der südlichen Niederlande wurde als Ausdruck katholischen Triumphs verstanden. Für den aus Rom kommenden Künstler waren dies beste Voraussetzungen, zumal sich hier ganz im Gegensatz zum andauernden Konkurrenzwettkampf in Italien beste markttechnische Aussichten boten. Darüber hinaus trug die Ausbildung eines höfischen Lebens nach internationalem Vorbild durch den Erzherzog zu einem vermehrten Bedarf an bildlicher Repräsentation bei. Und neben allen Effekten einer Rekatholisierung: auch die private Kunstpatronage, die ihn jetzt in Antwerpen seitens der städtischen Elite einholte, ließ Rubens wohl kaum mehr an eine Rückkehr nach Italien denken. Der Antwerpener Bürgermeister Nicolas Rockox, selbst beachteter Sammler und Kenner, bestellt Samson und Delilah als Kaminstück für sein Stadthaus (heute London, The National Gallery).

Bereits im Sommer 1609 wurde er zum Hofmaler des Erzherzogs Albert und seiner Frau, der Infantin Isabella bestallt, mit einem Jahressalär von 500

$\mathrm{Zu}$ Beginn des 16. Jahrhunderts unternahm Frankreich verstärkte Anstrengungen, sich strategisch aus der Umklammerung durch die Territorien der Habsburger zu befreien. Diese Auseinandersetzung wird weit in das 18. Jahrhundert hinein die europäischen Konflikte, auch die konfessionellen Grabenkämpfe überlagern.

Mit dem Unabhängigkeitskrieg der protestantischen Niederlande ab 1568, die im katholischen Frankreich Unterstützung gegen die spanischen Habsburger fanden, wurde nach etwa vier Jahrzehnten Kriege, 1609, ein auf zwölf Jahre befristeter Waffenstillstand zwischen Spanien und den Niederlanden vereinbart. Im gleichen Jahr vereinigten sich die katholischen Reichsstände unter Maximilian I. von Bayern in der katholischen Liga. Mit dem Tod des franzősischen Königs Heinrich IV., der einen Tag nach der Krönung Maria de' Medicis ermordet wurde, entspannte sich das ganz Europa bedrohende Konfliktszenario wieder. 
Gulden, Befreiung von den Gildenregeln und von allen Steuern und Abgaben, ein mehr oder minder dem Adel vorbehaltenes Privileg. Das Bemerkenswerte an Rubens' sozialer Position als Hofmaler war die gewährte Freiheit zur Annahme privater Aufträge. Der Künstler nahm seinen Wohnsitz in Antwerpen und nicht am Hof der Regenten in Brüssel ${ }^{37}$. All das spricht für den Ruhm, der Rubens bereits vorauseilte und das Privileg erklärt, in Antwerpen eine Werkstatt unabhängig von der Gilde und mit dem Recht auf unbegrenzte Zahl von Gehilfen führen zu dürfen.

Es folgten sogleich Großaufträge, wie die Anbetung der Könige für das Rathaus, den Ort, wo man 1608 den 12jährigen Waffenstillstand zwischen den spanischen und den freien Niederlanden unterzeichnet hatte. In dieser dem ökonomischen Aufblühen der Stadt zuträglichen Aufbruchsatmosphäre scheint Rubens in kürzester Zeit den heimatlichen Kunstmarkt dominiert zu haben. Nur mit dem Aufbau einer durchorganisierten Großwerkstatt war der Nachfrage gerecht zu werden ${ }^{38}$. Welche Attraktivität dieser Ort gehabt haben muss, lässt sich an den Mitarbeitern wie Anthonis van Dyck, Frans Snyders oder Jan Bruegel d. Ä. ermessen. Innerhalb dieses arbeitsteiligen Wirtschaftsunternehmens waren die selbst berühmten Kollegen für genau abgegrenzte Aufgabenbereiche, Tierdarstellungen, Landschaft oder Stillleben, zuständig. Nur so konnte dem Bedarf, der dann zu knapp 3000 Werken führen sollte, entsprochen werden ${ }^{39}$. Den reibungslosen Ablauf der Produktion zu sichern, war auch deshalb nötig, da die Reisetätigkeit des Künstlers, sei es zu Zwecken der Auftragsakquise oder in Erfüllung seiner durch das Hofamt begründeten Absenzen, ein selbständiges Agieren der Werkstatt erforderlich machte. Es wird hier deutlich, wie sehr die Zeichnungen, die eigene Kunstsammlung und das damit immer weiter gesteigerte Repertoire hineinspielt. Noch aus dem Ausland konnten neu eingefahrene Aufträge der Werkstatt kommuniziert werden, um damit der Erwartung einer Klientel entsprechen zu können, die eine zügige Lieferung von Werken schätzte. All dies wurde flankiert durch eine Eigenwerbung, wie sie etwa durch die Rubensstiche erfolg$\mathrm{te}^{40}$.

${ }^{37} \mathrm{Zu}$ Rubens und Brüssel vgl. Sabine van SPRANG, Rubens et Bruxelles, une relation plus que courtoise, in: Rubens - L'atelier du génie, S. 12-17.

${ }^{38}$ Zur Rubens' Werkstattorganisation vgl. Arnout BALIS, Rubens et son atelier: une problématique complexe, in: Ausst. Kat. Bruxelles 2007, S. 30-51.

${ }^{39}$ Maßgeblich ist hier das umfassende Corpus Rubenianum Ludwig Burchard (1968 ff.), in 26 Bänden geplant.

40 Die Rubensstecher, Ausst. zum 400. Geburtstag von Peter Paul Rubens, 2. Aug. bis 17. Sept. 1977, Museum der Bildenden Künste Leipzig, hrsg. von Karl-Heinz Mehnert sowie Erich HuBALA, Rubens in der Graphik, Würzburg 1977. Mit seinem Jugendfreund Balthasar Moretus, für den er eine Auferstehung anlässlich des Begräbnisses von dessen Vater malt, erhält sich Rubens ein für die Verbreitung seiner Werke im Stich essentielles Instrument. Moretus wurde 1610 Leiter der Antwerpener Presse Plantin, der wohl beruhm- 
Stellt man seine Auftragsarbeiten in eine Reihe, so fällt für die 1620er Jahre eine Verschiebung vom gehobenen Bürgertum zum Adel hin auf. Diese Jahre korrelieren mit dem Beginn seiner diplomatischen Tätigkeit und sprechen davon, wie sehr bei Rubens die politische Funktion mit der Fabrikation von Kunstwerken verflochten war. Ein wichtiger Katalysator, nicht zuletzt für die Entwicklung der Malerei hin zu einer Anschaulichkeit der Werke und ihrer Botschaften, war dabei der Auftrag der französischen Königinmutter, einen Bilderzyklus zu ihrem Leben zu schaffen.

\section{Paris}

Am 3. November 1620 kehrte Maria de Medici nach Paris zurück, um unverzüglich mit den Arbeiten zum Ausbau ihres Palastes beginnen zu lassen. Die Maßnahmen wurden wesentlich vom Kardinalminister Richelieu begleitet, der zur Auftragsvergabe an Rubens durchaus kritisch stand. Frühestens auf September 1621 sind die ersten Kontakte mit Rubens zu datieren. Am 11. Januar 1622 scheint Rubens in Paris gewesen zu sein und Ende Februar kam es in einem schriftlichen Vertrag zu einer Gemäldeserie, des sogenannten Medici-Zyklus. Die im Lauf des Jahres unternommenen Planänderungen, meist zu einzelnen Themen innerhalb der Bilderfolge, sind durch die Korrespondenz Peirescs sehr gut belegt ${ }^{41}$. Es war vertraglich vereinbart, dass Rubens die Bilder eigenhändig zu malen hatte, ,parfaite et peindre de sa propre main touttes et chacunnes des figures des tableaux", was kaum wohl heißen kann, dass alles eigenhändig gemalt, doch generell retouchiert werden mußte. Am 28. April 1623 fand - wohl in Antwerpen, kaum in Brüssel - eine Vorbesichtigung durch die Infantin Isabella statt, und im Mai trifft Rubens mit neun Gemälden in Paris ein, wo im folgenden Monat eine Begutachtung durch die Königin und Richelieu erfolgte. Im Februar 1625 kam dann Rubens mit den restlichen 15 Gemälden nach Paris an. Hier übergab er die in der Antwerpener Werkstatt vorgearbeiteten Bilder und tauschte die abgelehnte Tafel mit dem Weggang der Königin von Paris nach Blois mit derjenigen, die die Glückseligkeiten der Regenschaft darstellen. Schon 1626 erschien die erste gedruckte Description ${ }^{42}$, ein von Claude Barthélemy Morisot unter dem Titel

testen Druckerei Europas und humanistisches Zentrum zugleich. Hier ist es, wo Rubens Seine Illustrationen und Graphiken arbeiten wird.

${ }^{41}$ Kaum jemand unterhielt zu der Zeit ein umfassenderes europäisches Informationsnetzwerk als der Gelehrte, Antiquar und Sammler Nicolas Claude Fabri de Peiresc, der 1637 in Aix-en-Provence verstarb.

2 Zur ersten, handschriftlichen Beschreibung im Vorjahr, vom Historiographen Etienne Baluze gesammelt, vgl. die Wiedergabe des Ms. Baluze der BNF aus dem Konvolut der von Baluze zusammengetragenen Dokumente (BNF, Ms Baluze 232, fos 54-57). Vgl. 
Porticus Medicea verfaßter Text. Der Autor sollte dem Maler noch 1628 für seine kritischen Bemerkungen mit der Zusendung der zweiten, korrigierten Auflage danken.

Die Verbannung der Königin im November 1630 führte zur Einstellung aller Arbeit, so auch der mit Rubens vereinbarten zweiten Galerie zu Leben und Taten Heinrichs. Ab 1631 war dann Rubens mit der Vertretung der im Kölner Exil lebenden Königinmutter in den Verhandlungen mit Frankreich betraut ${ }^{43}$.

Seit Emile Michels Monographie von 1902 und Otto von Simsons Dissertation von $1936^{44}$ ist eine unüberschaubare Anzahl von Beiträgen zur MediciGalerie erschienen. Neben allem historiographischen Interesse macht vor allem die Frage nach der Kapazität der Malerei, zu einer Apotheose von Herrschaft beizutragen, die Auseinandersetzung mit dem Werk spannend ${ }^{45}$. Bereits in den als Propädeutikum lesbaren Zyklen des Decius Mus $(1616 / 17)^{46}$ und des Konstantin (1622) übte Rubens die Überblendung und Verwicklung der Erzählzeiten ein. Es ging nicht mehr nur darum, mit antiquarischer Gelehrsamkeit antikes Personal und Göttergeschichten auf das historische Agieren des Herrschers zu beziehen, quasi als Topologie und Präfiguration. Die fast schon journalistische Zeitgenossenschaft wurde betont. Sie verzichtete nicht darauf, sich als Fortwirken der Antike und als Einlösung ihrer Tugendqualitäten auszugeben. Rubens' Malerei vermag es, diesen Konnex unmittelbar einsichtig zu machen. Mit dem mythologischen Portrait im Reigen des antiken Assistenzpersonals findet die Transzendierung des Jetzt anschaulich statt. Es handelt sich hier nie um eine bloße Applikation oder Parallelisierung. Die malerisch nicht unterscheidbaren Sphären, das Ineinanderweben von zeitgenössischer und mythischer Bewegung und Aktion führt zu einer Überblendung und Durchdringung von Zeitebenen, die das aktuelle Ereignis als Verlebendigung sowohl eines antiken Wollens als auch antikisch heroischer Formen formuliert. Diese Bewegung zum ununterscheidbaren Ineinanderverweben resultiert bei Rubens aus dem Studium der Figurerfindung, der Kenntnis ihrer plastischen Werte und raumgreifenden wie raumbildenden Funktionen in Abhängigkeit von Licht und Farbe. Hier wer-

Bernhard WEHLEN, „Antrieb und Entschluss zu dem was geschieht" - Studien zur MediciGalerie von Peter Paul Rubens, München 2008, S. 237.

${ }^{43}$ Ab 1671 verlassen dann die Gemälde von Rubens das Palais du Luxembourg. Hiermit ist in etwa der Zeitrahmen der Querelle du coloris (1671-1700) abgesteckt.

44 Otto von SiMSONS immer noch lesenswerte Arbeit: Peter Paul (1577-1640): Humanist, Maler und Diplomat, Mainz 1996.

${ }^{45} \mathrm{Zu}$ Befragung der Gemäldefolge im Blick auf ihre Anschaulichkeit, im Gegensatz zu den wie auch immer naheliegenden, historisch politischen Konnotationen, vgl. die Dissertation yon Bernhard WEHLEN, Antrieb und Entschluss (wie Anm. 40).

${ }^{46}$ Vgl. hierzu die Dissertation von Susanne TAUSS, Dulce et decorum? Der Decius-MusZyklus von Peter Paul Rubens, Osnabrück 2000. 
den die malerischen Formen zu Handlungsträgern einer bildlichen Allegorie. Und es ist diese Dramaturgie der Versinnlichung, die zu einer überzeitlichen Verbildlichung der Macht führt ${ }^{47}$. Im Medici-Zyklus kalkuliert Rubens den Ort der Galerie in diese Lichtregie mit ein ${ }^{48}$. Jacob Burckardt erkannte dies früh.

Die zahlreichen Verweise auf Werke des eigenen Euvres sind Zeugnis des von Rubens konsequent erarbeiteten Konzepts. Sie haben auch einen werbestrategischen Effekt, wenn im Bild 24 des Medici-Zyklus die Figur der Königin von Chronos gepackt wird und an die Konstellation im Münchner Leukippidenraub denken lässt. Oder wenn die Drei Grazien in der Erziehung der Königin zur leibhaftigen und wirkmächtigen Realpräsenz transzendenter Kräfte werden, die das Regieren der Herrscherin durchwirken ${ }^{49}$. Zieht man die vielen Ölskizzen von Rubens zurate, scheint alles vom ersten Bildgedanken her präfiguriert. Es ist dieser Einfall, kaum mehr die Ausführung im Großatelier, der den künstlerischen Wert der Arbeiten ausmachte.

Zweifellos kommt im Medici-Zyklus Rubens' Innovationskraft zum Ausdruck, die in der Durchdringung zeitgenössischer Geschichte und allegorischer Transzendenz liegt. Doch Rubens verzichtet mit seiner Überhöhung der Regentin zugleich auf deren Idealisierung. Die Bilderserie zeigt aber auch, wie sehr man im Kontext machtpolitischer Balancen auf die Details der Bildsprache reflektierte. Das lässt sich an den zahlreichen Korrespondenzen über Detailfragen des Costume und über den Wechsel von Themen ablesen. Die Fähigkeit des Malers, politische Verhältnisse in komplexer Bildsprache auszudrücken, wurde bereits durch die Zeitgenossen thematisiert. Es war der noch mit Rubens bekannte Joachim Sandrart, der 1675 die Verquickung von diplomatischer Tätigkeit und malerischem Knowhow thematisierte. Das war

47

Wenn die „Wünschbarkeit allegorischer Zuthaten und Maschinerie, sobald aus sachlichen, politischen, kirchlichen etc. Gründen historische Thatsachen gemalt werden sollten, deren Hergang an sich schwer oder gar nicht malbar waren. Genau besehen werden dann vorzugsweise eben die allegorischen Gestalten das handelnde Element im Bilde; der innere Antrieb der Thatsachen wird in sie verlegt". Vgl. Jacob BURCKHARDT, Neuere Kunst seit 1550 , aus dem Nachlaß, hrsg. von Eva Mongi-Vollmer und Wilhelm Schlink, München [u. a.] 2006: Belgische Malerei des 17. Jahrhunderts, Peter Paul Rubens, unter der Überschrift „Geschichtliche Darstellung mit Hülfe der Allegorie“, S. 430. Hier ist allein durch die Titeleien der Kapitel eine wunderbare Übersicht der Bildgattungen und Themen gegeben.

${ }^{48}$ Palais du Luxembourg, von Salomon de Brosse ab 1615 begonnen und während Rubens' Arbeiten am Zyklus noch unvollendet, von der Regentin von 1625 bis zur ihrer Verbannung 1631 bewohnt. Die Galerie ist eine Neufassung der Idee des antiken Porticus oder einer Wandelhalle. Der Zyklus zeigt die wesentlichen Stationen des Lebens der Maria de Medici und mündet mit dem letzten Gemälde in die Apotheose der Wahrhaftigkeit, von der Zeit emporgehoben.

$\mathrm{Zu}$ den zeitgenössischen Impetustheorien, hier insbesondere im Kontext des Mysterium Cosmographicum Keplers, vgl. WEHLEN, Antrieb und Entschluss (wie Anm. 40), S. 145. 
mehr als bloßes Künstlerlob, denn Rubens verwandte die Reise nach Paris in der Tat auf diplomatische Verhandlungen.

Man gewinnt den Eindruck, ohne die Vertrautheit des Malers mit den politisch-diplomatischen Notwendigkeiten wären seine Bildlösungen so nicht möglich gewesen. Wenn Rubens im Gemälde des Medici-Zyklus Heinrich IV. empfängt das Bildnis der Maria de Medici (Paris, Musée du Louvre) dem König das Tableau in allegorischer Szenerie vorhält (ein Gemälde, welches Frans Pourbus in Italien zu diesem Zwecke angefertigt hatte), dann ist hier viel von der Funktion eines interhöfischen Bilderverkehrs zu sehen, die die Künstler in den Wettbewerb der Hofhaltungen einstellt. Dieses kunstpolitische Beziehungsfeld, welches dem auf Reisen geschickten Künstler mehr zutrauen muss als die Vervollkommnung seiner Malerei, wird im Laufe fortschreitender Mobilität immer enger geknüpft werden. Der daraus resultierende, zwanghafte Automatismus, im Wettbewerb bestehen und übertreffen zu können, ist Movens der Entfaltung der Künste. Voraussetzung für das bildkünstlerische Werk, die Bildsprache und die Künstlerpersönlichkeit ist die Mobilität, die über die geographischen Implikationen hinaus eine soziale Mobilität einschließt, ja, letztere scheint als Ziel der ersteren auf.

\section{Bilddiplomatie}

Bedeutung und Anteil des Bildermachens auf dem diplomatisch-politischen Parkett der europäischen Häuser darf für das 17. Jahrhundert nicht unterschätzt werden. Die Bedürftigkeit der Macht, ihrem Willen bildhaften und damit wirkmächtigen Ausdruck zu verleihen, hat wohl die Herausbildung des Typus eines Künstlerdiplomaten maßgeblich befördert. Doch nur im Fall des Peter Paul Rubens scheint die Synergie, die sich mit seinem bildkünstlerischen Werk im Kontext seiner politischen Missionen einstellt, so schlagkräftig und zugespitzt. Das Bild wird Teil des diplomatischen Kalküls, nicht nur des auftraggebenden Hofes, sondern des Künstlers selbst.

Die häufig zitierte Briefstelle aus Rubens' Korrespondenz vom 22. April 1622 an Pierre Dupuy, dem durch das Pariser Parlament bestallten Historiographen: „Ich für meinen Teil wünschte, daß die ganze Welt im Frieden sei und daß wir statt eines eisernen ein goldenes Zeitalter hätten", hat immer wieder zu einer Stilisierung des Künstlers beigetragen, die hier mehr sah als eine rhetorische Formel ${ }^{50}$. Es wäre naiv, die in der Korrespondenz des Künst-

${ }^{50}$ Zur Korrespondenz von Rubens vgl. Die Correspondance de Rubens et Documents épistolaires concernant sa vie et ses œuvres, hrsg. von Max Rooses [u. a.], Anvers 18871909; in der Übersetzung: Otto ZoFf, Die Briefe des P. P. Rubens (1918), sowie Ruth Saunders MAGURN, The Letters of Peter Paul Rubens, Cambridge (Mass.) 1955; ferner 
lers immer wieder anzutreffenden Beteuerungen wörtlich zu nehmen und sie nicht in ihrer Funktion als Stilmittel und Formel sprachlichen Taktierens zu sehen. Begrifflich ist Rubens von der Lehre Niccolo Macchiavellis (oder Giustinianis) nicht weit entfernt. Doch wie argumentieren seine Bilder, insbesondere die allegorischen Malereien rund um die Thematik von Krieg und Frieden?

Rubens' Diplomatenblick ist ganz auf die europäische Friedensordnung gerichtet. Man mag in ihm durchaus den auf ein goldenes Zeitalter visionierenden Malerfürsten sehen, der das Mittel von Intrige und Krieg im zeitüblichen Sinn als Instrument der Politik anerkennt. Ulrich Heinen hat jüngst die Wunschvorstellung des friedliebenden Kunstlerfürsten dekouvriert und auf die Nähe zur zeitgleichen Traktatliteratur verwiesen, etwa wenn Rubens für die zweite Auflage der Anleitung zum Gesandtenwesen des Frederik de Marselaer ein Titelkupfer arbeitete ${ }^{51}$. Die Friedenssehnsucht, die in Rubens' Fall vor allem auf die Befriedung der geeinten Niederlande zielte, mag man im Euvre auch als Leitidee zahlreicher Allegorien ausmachen. Diese untersteht aber hier wie da der übergeordneten Instanz seiner Loyalität gegenüber der Souveränität der Habsburger. Heinens Analyse des Gemäldes der großen Kriegsallegorie (Die Folgen des Krieges, Florenz, Palazzo Pitti, 1637/38; Abb. 2) befragt den Künstler auf seine Haltung als Bilddiplomat. Wie nachhaltig das Gemälde auf das europäische Bildgedächtnis gewirkt haben muß, belegen die zeitgenössische Verbreitung (in Tapisserien und Stichen) bis hin zu Picassos Rezeption für sein Weltausstellungsgemälde Guernica. Der Autor zeigt auf, wie das Gemälde in der Kunstgeschichte seit Jacob Burckhardt und Friedrich Waagen als (aus deutscher Sicht) nationales Emblem des Dreißigjährigen Krieges instrumentalisiert und als resignatives Trauern des Künstlers fehlinterpretiert wurde. Die antikatholische Dekontextualisierung entpolitisiert Bild und Maler zugleich. Das steht gegen das eindeutige Selbstzeugnis, das der Künstler dem Gemälde an Justus Sustermans und seinen Empfänger, den Großherzog der Toskana, mit auf den Weg gab ${ }^{52}$. Die eindeutigen Verweise auf Lukrez und Vergil (De rerum naturae und die Aeneis) begleiten und bereichern die Bildlektüre eines auf die konkreten historischen Kriegsereignisse bezogenen Gemäldes und machen es zu einer Art „Verführung zur Kriegsbereitschaft“ und Bekräftigung der „Gefolgschaftstreue“. Es ging um die strategisch-taktische Verbindung Antwerpens mit Oberitalien, hier Florenz, und die Bedrohung durch die vordringenden Franzosen. Das Bild, wel-

\footnotetext{
Hans KauffmanN, Peter Paul Rubens im Licht seiner Selbstbekenntnisse, in: WallrafRichartz-Jahrbuch 17 (1955), S. $181 \mathrm{ff}$.

${ }^{51}$ Frederik de MARSELAER, Legatus, Antwerpen 1626. Ulrich HEINEN, Rubens' Bilddiplomatie im Krieg (1637/1638), in: Mars und die Musen - Das Wechselspiel von Militär, Krieg und Kunst in der Frühen Neuzeit, hrsg. von Matthias Rogg [u. a.], Berlin 2008, S. $151-178$.

${ }^{2}$ Vgl. HeINEN, Rubens' Bilddiplomatie (wie Anm. 51), S. 159-161.
} 
ches von der Hilfe Euanders für Aeneas kündet, meint zugleich die Casa Medici als Nachfolgerin des mythischen Gründerkönigs Etruriens und ist Aufforderung an den Großherzog Ferdinand II., Neffe der Maria de Medici, seine Neutralität fallen zu lassen, um seinen Bündnispflichten nachzukom$\operatorname{men}^{53}$.

Wenn heute zu lesen ist: „Das Gemälde ,Die Folgen des Krieges“ von Peter Paul Rubens kann man als eines der ersten Antikriegsbilder bezeichnen. Es ist ein kritisches Bild, kein Bild, das den Mächtigen schmeichelt! ... Mitten im Dreißigjährigen Krieg entstand es und mahnt zum Frieden ${ }^{\text {“54 }}$, dann zeigt das etwas von der geschichtsvergessenen Distanz, die zu nichts als zum naiven Fehlurteil führt.

Die Florentiner Kriegsallegorie zeigt links die im Schreiben des Malers an Sustermans als Europa benannte Personifikation, wie sie mit Mauerkrone auch im Antwerpener Wappen zu sehen ist. Rubens malt Propaganda für die habsburgischen Niederlande, ohne auf den Hintersinn einer intelligenten Dialektik zu verzichten. Die Verteidigung gegen die bedrohenden Franzosen, die Aufforderung, gegen die Einkesselung der nördlichen Niederlanden vorzugehen, zeigt auch, dass die Topographie der Mächte Europas nach anderen Kriterien funktionierte, als die uns vertrauteren, geopolitischen Vorstellungen des 19. Jahrhunderts. Wie eine übergeordnete, Machtfelder bespielende Instanz wirkt hier die Antike als Kraft der Geschichte. Europa, wie der Maler die Klagende in seinem Brief benennt, ist Symbol der gesamten Christenheit, und das Schicksal Antwerpens wird zur europäischen Frage.

\section{Rubens und die Nähe zur Macht}

Rubens von Beginn an die strategische Planung seines Aufstiegs als Maler mit Hilfe der Nähe zur Macht zu unterstellen, greift zu kurz. Gute Beziehungen allein hätten hier kaum weitergeholfen. Die Begabung des Malers steht ebenso außer Frage wie das günstige Beziehungsnetzwerk zu Beginn seiner Karriere. Es war insbesondere das Reisen, welches ihm dazu verholfen hat, daraus ein europaweites Netzwerk zu gestalten. Die Vielsprachigkeit von Rubens, wie sie sich in seinen Briefen in Latein, Flämisch, Französisch und Italienisch ausdrückt, ist Resultat dieses europäischen Geistes. Das Einstellen in den intellektuellen Diskurs seiner Epoche zeitigte nicht zuletzt den Nachruhm. Doch die Selbstverständlichkeit, mit der der Maler seinen Ruhm und sein Ansehen sichtbar machte, erstaunt noch heute. Die Pracht seines Ant-

53 Das Bild war dann Teil der großen Sustermans-Sammlung am Florentiner Hof, dort, wo mit den versammelten zahlreichen Adelsportraits das höfischen Netzwerk Europas abermals vervielfältigt wurde.

$54 \mathrm{http}: / /$ www.onlinekunst.de/frieden/rubens.html. 
werpener Haushalts war sprechender Ausdruck des sozialen Status, der in Rückkopplung selbst wiederum Bilderpreise wie Nachfrage schürte. Die gesamte Lebensführung, das sog. Rubenshaus, das bei allen Veränderungen durch die Jahrhunderte einen Eindruck vom Selbstbild vermittelt, ist auch durch das eigene, gemalte Programm und die Antikensammlung ${ }^{55}$ als gedoppelte Repräsentation von Kunst und Bildung des Hausherrn zu verstehen. Dieser Musealisierung des eigenen Selbst, als Werkstatt des Apelles, eines pictor doctus, der gewohnt war, zu Pferde auszureiten, steht Rubens als naive Figur der Zurückhaltung und Friedensliebe gegenüber, hinter der sich in Wahrheit eine Selbstauffassung entdecken lässt, die keinen Grund hatte, sich der Tugend der Bescheidenheit zu verschreiben. In dieser Inszenierung ist der Maler zum Ende seiner Karriere zu Pietro Paulo Rubens, Ritter und Herr von Steen geworden.

\section{Reisen in diplomatischen Auftrag - Madrid, London}

1640 ersteigerten die Agenten Philipp IV. eine größere Anzahl von Rubenswerken, darunter eines seiner bekanntesten, den Liebesgarten. Damit ergänzte der spanische König die in Europa wohl erlesenste Bildersammlung durch Werke des Malers, der selbst in seinem Auftrag wesentlich zur Ausgestaltung des Bildprogramms der Madrider Residenzenlandschaft beigetragen hatte.

Während des Aufenthalts im Herbst und Winter 1628/29 hatte der Flame, neben seinen Arbeiten zum Reiterportrait des Königs, freien Zugang zu den königlichen Sommerappartements. Diese seit der Thronbesteigung 1621 mehr und mehr ausgebauten Appartements waren jetzt nicht in Gebrauch, beherbergten aber die Gemäldeserie Tizians, die unter der Bezeichnung Poesie bereits von Cassiano dal Pozzo während seines Frühjahrsaufenthaltes 1626 mit Cardinal Francesco Barberini in Madrid beschrieben worden war ${ }^{56}$.

55

${ }^{55} \mathrm{Zu}$ Rubens als Sammler siehe A House of Art: Rubens as Collector, Ausstellungskatalog Antwerpen, hrsg. von Kristin Lohse Belkin [u. a.], Museum Rubenshuis, 2004. Es ist bezeichnend, dass Rubens die Sammlung des englischen Botschafters Sir Dudley Carleton erwarb, welche dieser als Diplomat in Venedig zwischen 1610 und 1615 zusammengetragen hatte. Ein Prestigegewinn sondergleichen, der mit dem Verkauf der Sammlung an den Herzog von Buckingham für York House nochmals gesteigert werden konnte, da die Sammlung selbst als Ausdruck von Rang und Bildung zu werten ist. Die Bildersammlung des Künstlers, die 1640 inventarisiert wurde, verzeichnet Gemälde höchsten Ranges, wie sie einer fürstlichen Sammlung gut zu Gesicht gestanden hätten, darunter zahlreiche Werke von Tizian, Perugino und Correggio. Nach dem Erwerb des Landschlosses Het Steen wird die Imitation adeliger Lebensführung vollends offenkundig, Hier zeugen die vielen Landschaften und Veduten, ganz so wie es der adeligen Konvention entsprach, auch vom eigenen Besitz.

${ }^{56}$ Die Beschreibung der Sommerappartements vom Juni 1626 in der Bibliotheca Vaticana, Ms. Barb. Lat. 5689, ff.120v-123, wiedergegeben von Mary CRAWFORD VOLK, Rubens in 
Die am 15. August 1628 angetretene Reise nach Madrid im Auftrag Isabellas sollte den spanischen König über die Ergebnisse der Verhandlungen mit den nördlichen Provinzen unterrichten. Sie war jedoch zugleich Reise in eigener Sache, da er sie mit Gemälden im Gepäck unternahm, die er dann auch an den König verkaufen konnte. Er erhielt darüber hinaus den Auftrag zu fünf weiteren Portraits der königlichen Familie.

Und auch mit der Reise nach England wird deutlich, wie die diplomatische Aufgabe dem Maler weit über seine Heimat hinaus Europa als Absatzmarkt erschließt. In London erhält er, parallel zu seinem höfischen Auftrag, als Privatperson die Gelegenheit zur Ausstattung des Banket-House. Seine Dekkenausgestaltung in Whitehall kann als einer der lukrativsten Aufträge schlechthin gesehen werden. Ob durch Ambrogio Spinola, wie uns Bellori berichtet, oder vom Herzog von Buckingham, der während seines Parisaufenthaltes Rubens kennengelernt hatte, sei dahin gestellt, jedenfalls wird man ihn bei Isabella als Kandidat für die diplomatischen Dienste empfohlen haben, um in England den Frieden zwischen Philipp IV. und Karl I. zu verhandeln $^{57}$. Rubens erfüllte nahezu alle Voraussetzungen (Bildung, Sprachkenntnisse, Eloquenz, tadelloser Ruf) für den diplomatischen Dienst. Da ihm das Adelspatent fehlte, sollte man davon ausgehen, dass der Maler de facto den rangniederen Diplomaten zuzurechnen ist und als Resident und nicht etwa als Legat oder Botschafter auftrat. Wie auch immer sein persönlicher Erfolg bei den Friedenverhandlungen zu veranschlagen ist: nimmt man die Kunst als Gradmesser, so muss die Londoner Mission als äußerst fruchtbringend gewertet werden. Während der Verhandlungen beider Länder übergab Rubens dem englischen König ein Gemälde zum Thema Krieg und Frieden (heute London, National Gallery, Minvera die Allegorie des Friedens vor Mars schützend). Den tatsächlichen Einfluss der in den Gemälden thematisierten Stellungnahmen auf die Realpolitik lassen sich nicht nachweisen. Doch am 15. November kam es zum Friedensschluss beider Länder. Die Verleihung des Titels eines Magister Artium der Universität Cambridge einige Wochen zuvor sowie die Erhebung des Flamen in den Ritterstand im Folgejahr (3. März 1630) hat wohl nicht wenig von diplomatischer Gepflogenheit, wenn der englische König damit dem spanischen gleichzog. Der Friedensvertrag selbst wurde selbstredend nicht von einem Maler, sondern vom eigens nach London angereisten Botschafter, Don Carlos de Colonna, sowie in Madrid vom englischen Botschafter Sir Francis Cottington unterzeichnet. Für

Madrid and the decoration of the King's summer apartments, in: Burlington Magazine CXXIII (no. 942, Sept. 1981), S. 513-529.

57 Roger de Piles bezieht sich in seinem Abrégé de la vie des peintres von 1699 auf die vom Neffen an ihn ubersandte lateinische Vita von Rubens. Quellen, die uns hingegen verlässlich Auskunft über seine Tätigkeit als Staatsmann liefern, existieren so gut wie nicht. 
Rubens jedoch war die Reise nach England in mehrfacher Hinsicht lukrativ und beförderte nicht zuletzt seinen Ruhm auf der Insel ${ }^{58}$.

Die im Verlauf seiner Diplomatentätigkeit geknüpften Kontakte sollten ihm erhalten bleiben. Seine Laufbahn als Diplomat neigt sich mit dem Fall der Stadt Maastricht 1632, nachdem die Position der Habsburger militärisch heikel geworden war, dem Ende zu. Es ging für die Niederlande um die Abwägung nationaler Belange, die mit den Interessen der Habsburgerdynastie nicht deckungsgleich waren, so dass der südniederländische Adel Verhandlungen mit dem Norden aufgenommen hatte. Hier war es an Rubens, im Auftrag der Regentin einzugreifen, und prompt insistierte der Herzog von Aarschot darauf, dass die niedere Herkunft des Malers zu einer Amtsenthebung führen müsse. Ausgestattet mit dem Titel eines Sécrétaire du Conseil Privé $d u$ Roi forderte der Maler auch Willem van Oldenbarnevelt heraus, der ihn „zu hoffärtig für einen Maler" hielt. Das Ende seiner Karriere als Diplomat wurde dann sicherlich durch den Tod der Infantin Anfang Dezember 1633 befördert. Doch weiterhin mit Diplomatengestus aufzutreten, war seiner Stellung auch als Künstler dienlich, und man muss es als späte Verklärung lesen, wenn in der lateinischen Vita das Ende der Karriere mit der Friedensliebe des Künstlers erklärt wird.

\section{Rubens und Europa}

Das etwas schräge, eingangs zitierte Bild des Kunsthistorikers Swoboda, der das Jahrhundert unter die Fahne einer Wachablösung stellte, macht bei aller Projektion deutlich, dass hier eine Verschiebung dessen auftritt, was wir mit der Eröffnung einer europäischen Perspektive auf ein neues Europaverständnis umschreiben wollen, sei es als Krise des europäischen Geistes (Paul Hazard) oder als Aufbruch.

Bei kaum einem Künstler lässt sich, nicht zuletzt durch die Reisetätigkeit und die damit verbundene Weitung von Horizont und Themen, die Konstellation des Jahrhunderts besser begreifen. Umfassend haben diese Bilder mit einem neuen Europaverständnis zu tun. Man ist versucht, die Titelei des mit weiter Verbreitung rezipierten Werkes des Matthäus Merian, Theatrum Europaeum (erster Band von 1635, nachfolgend 21 Bände) ${ }^{59}$ auf die Bilderwelt von Rubens zu übertragen. Auch hier treten neue Bilder, aufgrund eigener

Zu Rubens' Rezeption in England im Kontext von Kunstmarkt und Kunsttheorie vgl. jüngst Bärbel KÜSTER, Natura auf dem Kunstmarkt - Ein fiktiver Dialog zwischen Kunsttheorie und Graphik, in: Druckgraphik Zwischen Reproduktion und Invention, hrsg. von Markus A. Castor [u. a.], Berlin [u. a.] 2010, S. 341-361.

59 Merian selbst betreute die ersten fünf Bände des bis 1738 fortgesetzten Werkes.
Meriastor [u. a.], Berlin [u. a.] 2010, S. 341-361. 
Anschauung und eigener Erfahrung, mit einigem Neuigkeitswert und gehörigen Empirismus zutage.

Merians erster Band beschrieb die Jahre des Dreißigjährigen Krieges, und wenngleich der Schauplatz der „wahrhafften Beschreibung aller Denckwürdigen Geschichten" die Reichsterritorien waren, machte das Frontispitz deutlich, dass es sich um eine europäische Angelegenheit handelte. Wie in Rubens' Bild von den „Folgen des Krieges“ war es die Erdkugel, die diesen Anspruch auf eine europäische Perspektive vertrat ${ }^{60}$. Auch Rubens setzte der im Nukleus bereits nationalen Konnotation des 17. Jahrhunderts eine transnationale, historisch orientierte Perspektive entgegen. Hier scheinen zwei Modelle in einem Amalgam und am Beginn einer Verschiebung vorzuliegen: Das Europa der Nationen sowie das kulturell und historisch determinierte Europa des Christentums, dessen Grenzen weniger topographisch als in der kulturellen Abgrenzung zu finden $\operatorname{sind}^{61}$. Man mag dieses Europabild auch als Abbild des politischen, kulturellen und ebenso ökonomischen Austausches sehen, der geradezu Lebensvoraussetzung Antwerpens war. In Rubens' Verteidigung der Einheit des Christentums mag sie als Sehnsucht nach der Einigung der europäischen Häuser aufscheinen. Das Europa der Christenheit, 1625 noch der Denkrahmen für Hugo Grotius' De jure belli ac pacis, seinem europäischen Völkerrecht, wird komplementiert durch die Europaidee des Erdteils, der sich aus der Abgrenzung von und der Bedrohung durch andere Kulturen (Perser, Araber, Osmanen) definiert. Die beiden Kulturmodelle, die sich hier ablösen sollen, scheinen sich für die Schaffensphase von Rubens gegeneinander zu verschieben $^{62}$. Die Ordnungsprinzipien, welche durch den Dreißigjährigen Krieg durcheinander geraten waren, haben durch die Vorstellung der ausbalancierten Kräfte, zwischen denen Rubens diplomatisch zu vermitteln hatte, stabilisiert zu werden. Diese Balance der Kräfte ist auch die bildimmanente Zauberformel des Malers Rubens. Die Vorstellungen vom Frieden im goldenen Zeitalter basieren wesentlich auf dem Bild Europa. Es ist das Gleichge-

${ }^{60}$ Die beigefügte Europakarte geht mit den Erläuterungen des Philipp Abelinus einher, der die kulturellen Wurzeln der europäischen Kultur (aus der jüdischen, griechischen und römischen) anklingen lässt.

${ }^{61}$ Dies touchiert die Idee des überlegenen alten Kontinents. Gerade die Bedrohungssituation durch Frankreich und die spätere Furcht vor der Universalmonarchie Ludwigs XIV. bedingt eine Vermehrung von Traktaten und Pamphleten, die Europa thematisieren. Vgl. Fritz WAGNER, Europa im Zeitalter des Absolutismus und der Aufklärung. Die Einheit der Epoche, in: Ders. (Hrsg.), Handbuch der Europäischen Geschichte, Bd. 4, Stuttgart 1968, S. 1-163. Es ist dann Richelieu, der die Literaturproduktion uber die topographische Abgrenzung unter dem Leitbild der "frontières naturelles" vorantreibt. Vgl. William F. CHURCH, Richelieu and Reason of State, Princeton 1972, insbes. S. $249 \mathrm{ff}$.

${ }^{62}$ Das entspricht etwa der von Fernand Braudel ausgemachten Hochzeit des italienischen Modells (1450-1650). Fernand BRAUDEL, Le modèle italien, Paris 1989, dt. u. d. T. Modell Italien, Berlin 2003. 
wicht, die Auflösung der widerstreitenden Kräfte, durch die Eingriffe der Götter auf Erden herbeigeführt.

Erst nach Rubens' Tod, mit dem Westfälischen Frieden von 1648, erfüllt sich der Abschied vom Denken Europas in der Konkurrenz der Häuser (Habsburg und Valois/Bourbon). Die europäische Staatengemeinschaft schien die zersplitterte Mitte des Kontinents als Feld von Ausgleich und Kriegstheater zu benötigen. Mit dieser strukturellen Verschiebung (von der Dominanz des Hauses Habsburg auf das Territorium der Reichsländer) wandelt sich das dynastische Ringen um die Vorherrschaft zur topographisch dominierten Auseinandersetzung auf dem Feld des politisch zunächst schwächsten Gliedes.

Die heute, wohl überlegt, in Brüssel implementierte Verwaltungszentrale eines Europabegriffs ist dabei, diese Wurzeln des kulturellen Europa hinter einer Wand von technischen Regularien zu versenken. Und heute reisen eher die Bilder als die Künstler, abgetrennt von ihren Kontexten und historischen Aufgaben. 


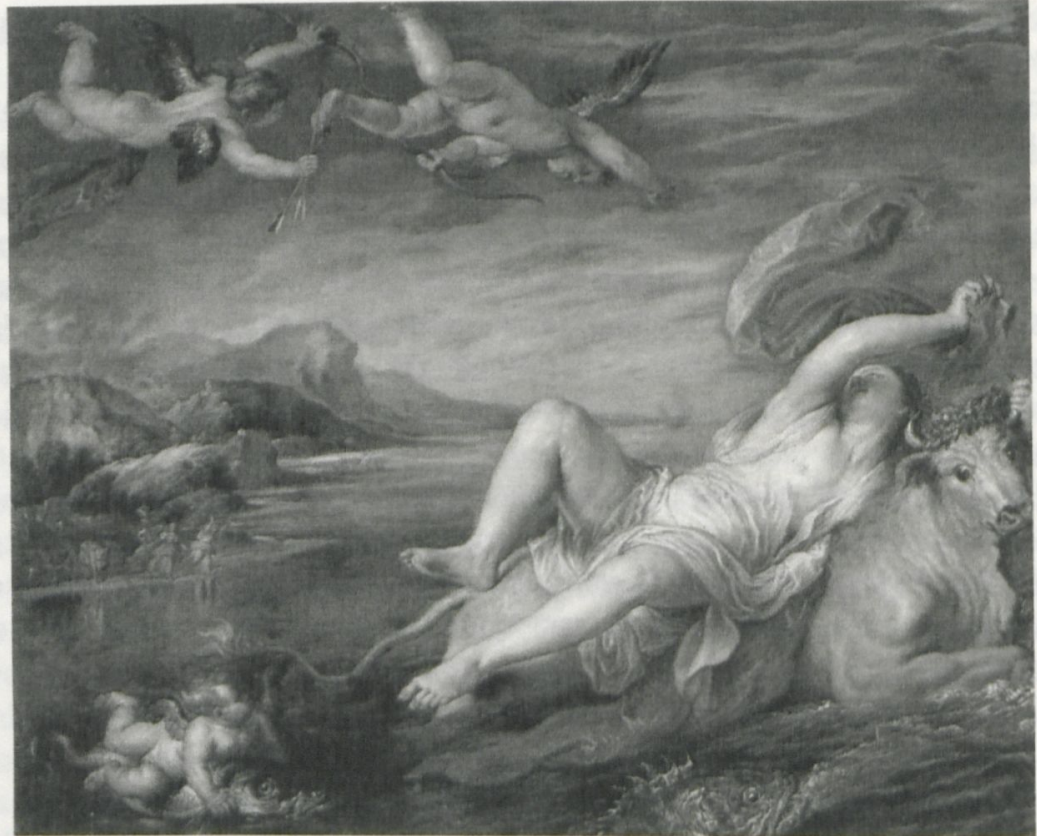

$A b b .1$

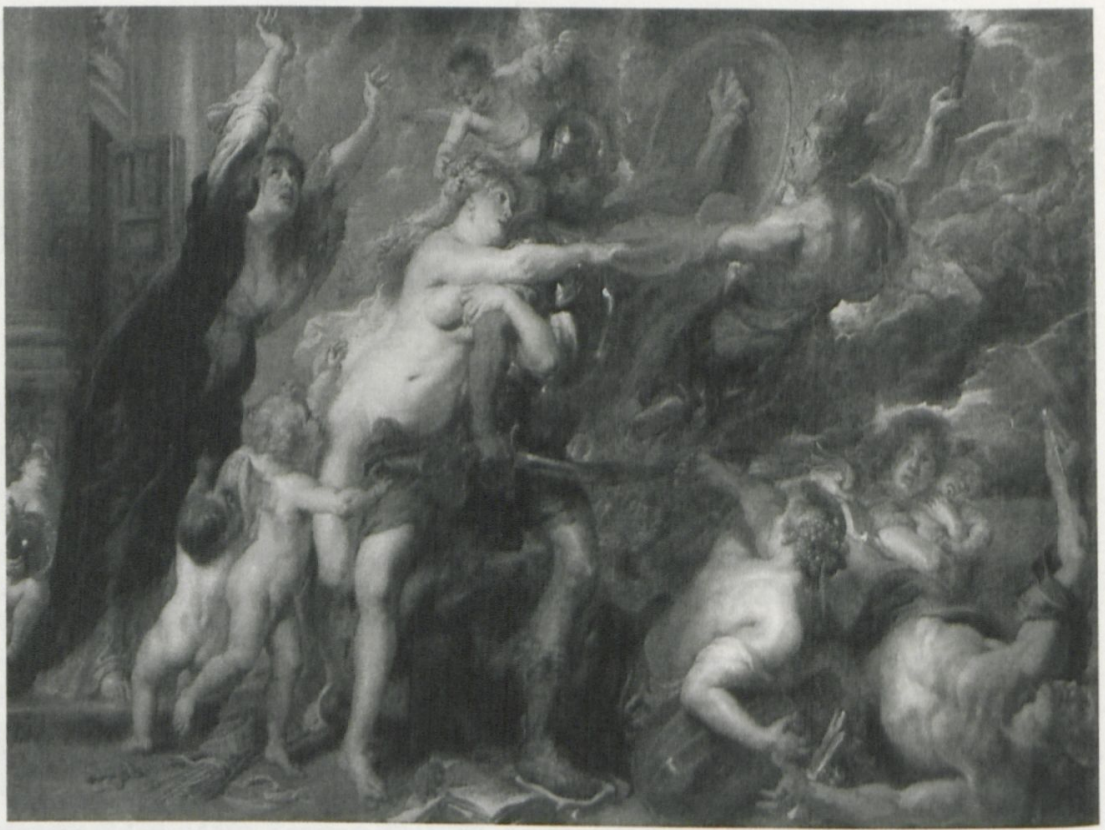

Abb. 2 